\title{
Spatial and Temporal Distribution of Slip for the 1992 Landers, California, Earthquake
}

\author{
by David J. Wald and Thomas H. Heaton
}

\begin{abstract}
We have determined a source rupture model for the 1992 Landers earthquake $\left(M_{W} 7.2\right)$ compatible with multiple data sets, spanning a frequency range from zero to $0.5 \mathrm{~Hz}$. Geodetic survey displacements, near-field and regional strong motions, broadband teleseismic waveforms, and surface offset measurements have been used explicitly to constrain both the spatial and temporal slip variations along the model fault surface. Our fault parameterization involves a variable-slip, multiple-segment, finite-fault model which treats the diverse data sets in a self-consistent manner, allowing them to be inverted both independently and in unison. The high-quality data available for the Landers earthquake provide an unprecedented opportunity for direct comparison of rupture models determined from independent data sets that sample both a wide frequency range and a diverse spatial station orientation with respect to the earthquake slip and radiation pattern. In all models, consistent features include the following: (1) similar overall dislocation patterns and amplitudes with seismic moments of 7 to $8 \times 10^{26}$ dyne-cm (seismic potency of 2.3 to $2.7 \mathrm{~km}^{3}$ ); (2) very heterogeneous, unilateral strike slip distributed over a fault length of $65 \mathrm{~km}$ and over a width of at least $15 \mathrm{~km}$, though slip is limited to shallower regions in some areas; (3) a total rupture duration of $24 \mathrm{sec}$ and an average rupture velocity of $2.7 \mathrm{~km} / \mathrm{sec}$; and (4) substantial variations of slip with depth relative to measured surface offsets. The extended rupture length and duration of the Landers earthquake also allowed imaging of the propagating rupture front with better resolution than for those of prior shorter-duration, strike-slip events. Our imaging allows visualization of the rupture evolution, including local differences in slip durations and variations in rupture velocity. Rupture velocity decreases markedly at shallow depths, as well as near regions of slip transfer from one fault segment to the next, as rupture propagates northwestward along the multiply segmented fault length. The rupture front slows as it reaches the northern limit of the Johnson Valley/Landers faults where slip is transferred to the southern Homestead Valley fault; an abrupt acceleration is apparent following the transfer. This process is repeated, and is more pronounced, as slip is again passed from the northern Homestead Valley fault to the Emerson fault. Although the largest surface offsets were observed at the northern end of the rupture, our modeling indicates that substantial rupture was also relatively shallow (less than $10 \mathrm{~km}$ ) in this region.
\end{abstract}

\section{Introduction}

The 28 June 1992 Landers earthquake is the largest well-recorded earthquake in the United States to date. The large rupture length $(70 \mathrm{~km})$ and long duration $(24$ $\mathrm{sec}$ ), in addition to the high quality and variety of data, provide an unprecedented opportunity to model the rupture history of this event with a variable-slip, finite-fault rupture model. The value of determining earthquake slip distributions and rupture time histories has been well established over the last decade. Constraints on slip duration and heterogeneity, rupture velocity, and faulting complexity have provided insights into the earthquake rupture process and allowed higher-quality forward predictions of ground motions (for a summary, see Wald, 1992). 
Unfortunately, it has always been difficult to evaluate the resolution and accuracy of these slip models and to compare results of different studies. This problem occurs in part because different studies rely on different data sets or subsets, and is further complicated by the various parameterizations and procedures used in determining faulting history. These two variables can be directly responsible for major differences in resulting fault models. To alleviate this particular problem, we have performed independent inversions of three important data sets for constraining the rupture process of the Landers earthquake using a single-fault model parameterization. We also explicitly include constraints from another important data set-observations of fault surface offset. In this way, we gain more confidence in our solution as we match more and more independent observations.

There are several important advantages in combining the multiple data sets. First, neither the geodetic nor the strong-motion stations uniformly cover the near-field region (i.e., one fault length). As a combined data set, the spatial sampling is enhanced. Further, the addition of the vertically propagating teleseismic body waves allows sampling of the focal sphere with up- and downgoing ray parameters that are not sampled well by the near-field waveforms, thereby enhancing vertical resolution of our models.

Second, the range of frequencies covered is from DC to $0.5 \mathrm{~Hz}$, allowing comparison of slip models which sample only co-seismic slip (teleseismic and strong motions) and co-seismic slip plus immediate afterslip (geodesy), if any occurred. As will be shown, the consistency of slip distributions derived from these two data bandwidths requires short-duration slip histories, and suggests little, if any, immediate afterslip.

Finally, the complexity of the Landers fault model parameterization precludes testing the entire temporal faulting parameter space (e.g., fully allowing variable rise times, rupture velocities, rupture delays, and the possibility of rerupturing, etc.). Consequently, a priori assumptions on the timing of the rupture must be made. Since the geodetically determined slip pattern is completely independent of the rupture timing, insisting that the final static slip in the waveform inversions also fit the geodetic data provides an independent check on any timing assumptions. This is a great advantage over bandlimited waveform studies alone, where there can be tradeoff between the rupture timing and the slip location. Of course, the geodetic data alone provide no information on the rupture evolution or temporal slip variations, so the waveform data, while more difficult to model, ultimately provide more information about the rupture dynamics.

Since the Landers earthquake occurred on a series of stepping fault segments, a further goal of this study is to image the history of rupture propagation from segment to segment. Dynamics of strike-slip step-overs have recently been addressed theoretically (Harris and Day, 1993), and we now have the opportunity to constrain the dynamic slips and stresses controlling the segmentation observationally (or, at least, one step removed). We further hope that being able to visualize this rupture process will bring particular aspects of the earthquake rupture process to light.

Critical to our investigation is our use of a uniform parameterization for many data sets. By representing slip on the fault with numerous subfaults, and slip on each subfault by the summation of many point sources over the subfault area, we can generate near-field static, strongmotion, or teleseismic synthetic Green's functions with identical fault models. Complete waveform strong-motion responses are calculated with frequency-wavenumber integration techniques, and teleseismic $P$ and $S H$ waveforms are simulated using the generalized ray methodology. The static displacements for each subfault are computed from the analytic expressions for slip in an elastic half-space. We then use a constrained, damped, linear least-squares inversion to determine the slip on each subfault. We also allow slip to occur in multiple time windows to accommodate complexity of the slip function on each subfault and to model variations in rupture times (effectively allowing the rise time and rupture velocity to vary spatially).

\section{Fault Rupture Model}

\section{Fault Parameterization}

We model the Landers earthquake with a fault model consisting of three linear, vertical fault segments as shown in map view in Figure 1 (hatchured lines) and displayed in cross section in Figure 2. As indicated in these figures, the three segments represent, from south to northwest, the Johnson Valley and Landers faults (strike $355^{\circ}$ ), the Homestead Valley Fault (strike $334^{\circ}$ ), and the Emerson and Camp Rock faults (strike $320^{\circ}$ ).

This segmentation was chosen based on the locations of the surface rupture expression (Sieh et al., 1993) and the aftershock seismicity (Hauksson et al., 1994), both of which are depicted in Figure 1. The three segments generously contain and closely approximate the correct strike of the fault segments which ruptured. Noting that significant seismicity, though little surface slip, occurred south of the epicenter (star), we allowed for the possibility of extended rupture into this region as well.

The choice of three segments represents a trade-off between accommodating the obviously complex faulting geometry observed at the surface, and the desire to keep the problem tractable. For example, the straight segment approximation to the complex surface trace and aftershock pattern near strong-motion station LUC (Fig. 1) fits the overall fault trend, but may be inadequate to 
properly model the higher-frequency aspects of the waveforms recorded there. Fortunately, the complexity of the faulting at depth appears to be less intricate than the surficial offset would lead us to believe (see numerous cross sections in Hauksson et al., 1994).
We discretize the three fault planes into a total of 186 subfaults (Fig. 2) in order to represent variable slip along the fault. The fault parameterization and modeling procedure we employ is after that described by Hartzell and Heaton (1983).

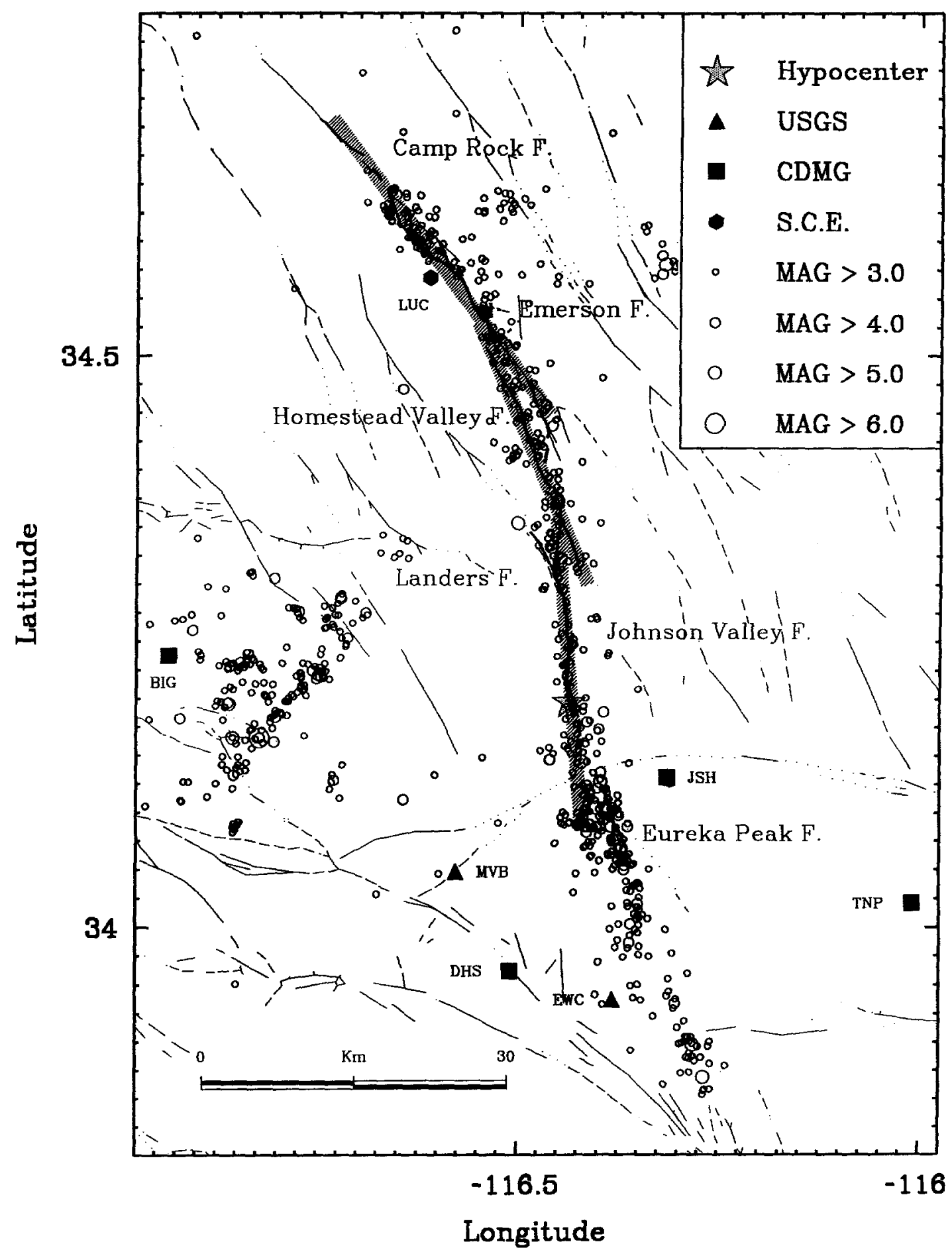

Figure 1. Map showing the fault surface offset (dark lines) and the surface projection of the three fault segments of the model fault (hatchured lines). Aftershocks are shown as circles with magnitude as given in the inset. Solid symbols mark locations of strong-motion stations. 


\section{Synthetic Green's Functions}

The subfault motions are obtained by summing the responses of nine point sources equally distributed over the subfault. For both the teleseismic and strong-motion Green's functions, each point source is lagged appropriately in time to include the travel-time difference resulting from the varying source-to-station positions and to simulate the propagation of the rupture front across each subfault. Thus, all subfaults separately include the correct effects of directivity. In total, 1674 point-source Green's functions are summed to construct each of the geodetic, teleseismic, and strong-motion synthetics at every station.

Point-source responses for the teleseismic $P$ or $S H$ body wave synthetic seismograms are computed using the generalized ray method (Langston and Helmberger, 1975). We include the responses of all rays up to two internal reflections in a layered velocity model (Table 1), including free surface and internal phase conversions. A $Q$ operator (Futterman, 1962) is applied with the atten-
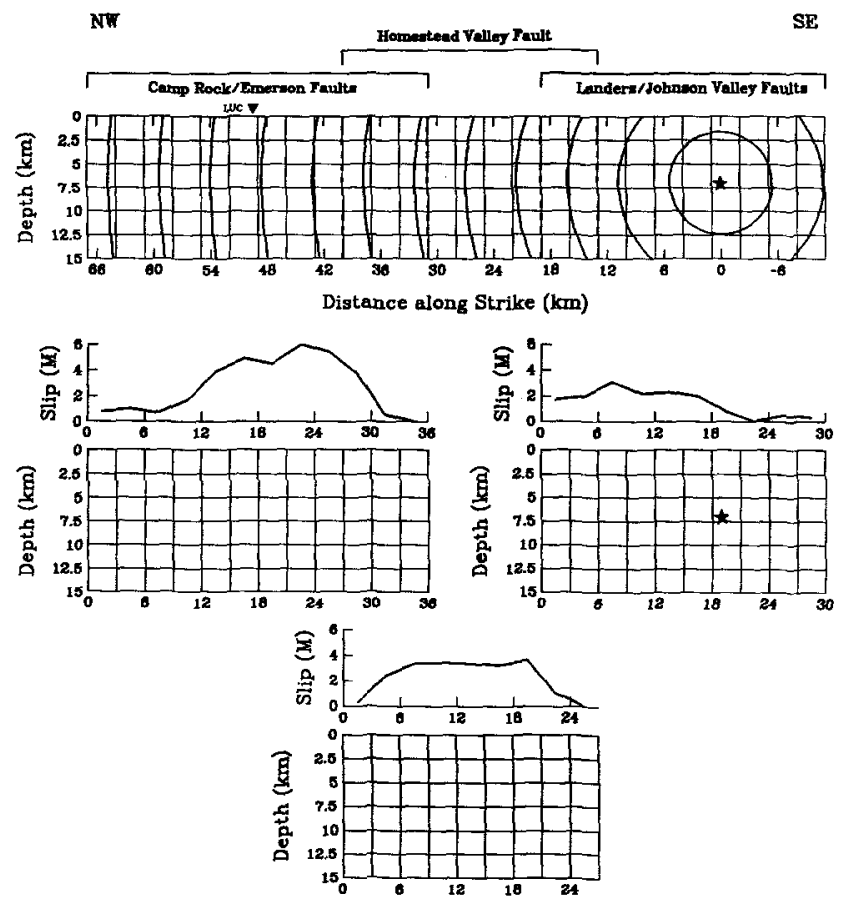

Figure 2. Fault model cross section (northwest on left, southeast on right) displaying the subfault discretization of the three model fault planes (bottom three faults) which make up the complete Landers fault model (top fault). Presented above each fault segment is the observed surface offset as averaged over each subfault length. The location along strike of station LUC is marked with a triangle, and the hypocenter is shown as a star. The circular curves depict the advance of the rupture front at 2 -sec intervals for a constant $2.7 \mathrm{~km} /$ sec rupture velocity. uation time constant $t^{*}$ equal to 1.0 and $4.0 \mathrm{sec}$ for $P$ and $S H$ waves, respectively.

The point-source responses for the strong-motion synthetics are computed for the same layered velocity model (Table 1) with a frequency-wavenumber ( $F-K)$ integration scheme for frequencies up to $2.0 \mathrm{~Hz}$. In practice, we calculate a master set of synthetics for $2-\mathrm{km}$ increments in depth from 0.1 to $15.1 \mathrm{~km}$ and for ranges between 0 and $180 \mathrm{~km}$, to allow for the closest and furthest possible subfault-station combinations. Then for each point-source-station pair, the required response (for a pure right-lateral, strike-slip mechanism) is derived by a linear interpolation of the closest Green's functions available in the master set. The linear interpolation of adjacent Green's functions is performed by aligning the waveforms according to their shear-wave travel times. The final subfault synthetic is obtained by the summation of nine point-source responses, appropriately lagged in time for the rupture delay.

For the geodetic modeling, the horizontal static displacements for subfaults are generated from the analytic expressions of Mansinha and Smylie (1971) for surface displacements resulting from a uniform displacement at depth. We approximate the earth as a Poissonian halfspace. The amount of slip on each subfault is later determined in the inversion process described below.

The source-region velocity model used to compute both the teleseismic and F-K Green's functions given in Table 1 represents a generic southern California crustal structure used for hypocentral location, modified by Jones and Helmberger (1992) to model broadband aftershock waveforms from the Landers sequence. We have also added a thin, slower layer to this model to better approximate elastic properties just beneath the strong-motion stations. The majority of strong-motion sites are characterized by either rock or shallow alluvium (Table 2). For the relatively low-frequency band used in this study $(0.077$ to $0.5 \mathrm{~Hz})$, all the "shallow alluvium" sites can be considered rock sites, consistent with our shallow velocity layer.

\section{Source Time Function and Rupture Velocity}

An added complication arises from the multiply segmented nature of the Landers rupture, forcing us to address the possibility of delayed or triggered rupture initiating on adjacent fault strands. Each subfault is allowed to slip in any of six identical 1-sec time windows following the passage of the rupture front, thereby allowing for the possibility of a longer slip duration or a locally faster or slower rupture velocity. Hartzell and Mendoza (1991) obtained very similar dislocation models for the 1978 Tabas, Iran earthquake $\left(M_{S} 7.4\right)$ using both a linear-inversion parameterizing slip with multiple time windows (as is done here), and also using a nonlinear iterative inversion which allows a single rupture at each 
point on the fault, but which allows the rupture velocity to vary. The time-window parameterization allows more flexibility to include rupture delays from one segment to the next, a possibility that must be allowed considering the nature of the Lander's rupture.

In earlier studies using the time-window parameterization (e.g., Hartzell and Heaton, 1983, 1986; Wald et al., 1990, 1991), only three time windows were employed. Here we face not only larger overall dislocations than the events of those studies (and hence potentially longer slip durations), but possibly more rupture complexity, considering the multiply segmented surface fault expression. Recently, up to 15 time windows were employed by Hartzell and Langer (1994) and Mendoza et al. (1994) to accommodate more slip complexity and longduration slip episodes from larger $M_{W} 8.0$ earthquakes. With multiple time windows, we can approximate three rupture characteristics: (1) variable, complex, or longduration local slip histories; (2) rupture velocity perturbations from the assumed uniform velocity; and (3) the possibility of rupture delay from one fault segment to the next. We will show in a later section that this parameterization is required for adequately describing the rupture development and does not unnecessarily add more degrees of freedom in the inversion.
A schematic diagram depicting the use of time windows is presented in Figure 3. For this example, only three windows are shown, but the ability to model local variations in particle displacements and rupture delays (rupture velocity variations) is apparent; rupture can be locally delayed as well as vary in duration. Substantial variability can be obtained with the six time windows we allow in this study. Although some roughness is introduced by the starting and stopping of slip in each time window, it is smoothed out by the low-pass filter applied in the bandpassed synthetics $(2 \mathrm{sec})$.

The initial rupture velocity is assumed to be a constant $2.7 \mathrm{~km} / \mathrm{sec}$, or about $75 \%$ of the shear-wave velocity in the main part of the source region (Table 1). We tried a range of values from 2.4 to $3.0 \mathrm{~km} / \mathrm{sec}$ but found $2.7 \mathrm{~km} / \mathrm{sec}$ to be most suitable. In this study, the dislocation time history in each time window is represented by the integral of an isosceles triangle with a duration of $1 \mathrm{sec}$. This slip function was chosen based on a comparison of the synthetic velocity pulse width for a single subfault with the shortest-duration velocity pulse width observed, as well as on prior experience with this inversion method. Each two 1-sec time windows are separated by $1 \mathrm{sec}$, so that they are adjacent in time and do not overlap (as shown in Fig. 3).

Table 1

Regional Velocity Structure

\begin{tabular}{ccccccr}
\hline $\begin{array}{c}V_{p} \\
(\mathrm{~km} / \mathrm{sec})\end{array}$ & $\begin{array}{c}V_{s} \\
(\mathrm{~km} / \mathrm{sec})\end{array}$ & $\begin{array}{c}\text { Density } \\
\left(\mathrm{g} / \mathrm{cm}^{3}\right)\end{array}$ & $\begin{array}{c}\text { Thickness } \\
(\mathrm{km})\end{array}$ & $\begin{array}{c}\text { Depth } \\
(\mathrm{km})\end{array}$ & \multicolumn{1}{c}{$Q_{p}$} & \multicolumn{1}{c}{$Q_{s}$} \\
\hline 3.80 & 1.98 & 2.30 & 1.5 & 1.5 & 100 & 30 \\
5.50 & 3.15 & 2.60 & 2.5 & 4.0 & 600 & 300 \\
6.20 & 3.52 & 2.70 & 22.0 & 26.0 & 600 & 300 \\
6.80 & 3.83 & 2.87 & 6.0 & 32.0 & 600 & 300 \\
8.00 & 4.64 & 3.50 & & & 600 & 300 \\
\hline
\end{tabular}

Table 2

Strong-Motion Stations

\begin{tabular}{lllll}
\hline Station & & L Latitude & W Longitude & Site \\
\hline AMB & Amboy & 34.560 & 115.743 & shallow alluvium \\
BKR & Baker, Fire Station & 35.272 & 116.066 & deep alluvium \\
BAR & Barstow, Vineyard and H St. & 34.887 & 117.047 & alluvium \\
BIG & Big Bear Lake, Civic Grounds & 34.238 & 116.935 & shallow alluvium \\
DHS & Desert Hot Springs & 33.962 & 116.509 & deep alluvium \\
EWC & East Wide Canyon & 33.937 & 116.381 & shallow alluvium \\
HSP & Hesperia, 4th and Palm & 34.405 & 117.311 & alluvium \\
JSH & Joshua Tree, Fire Station & 34.131 & 116.314 & shallow alluvium \\
LUC & Lucerne Valley, Power Station & 34.568 & 116.612 & shallow alluvium \\
MVB & Morongo Valley & 34.048 & 116.577 & alluvium \\
TNP & Twenty Nine Palms & 34.021 & 116.009 & shallow alluvium \\
YRM & Yermo, Fire Station & 34.903 & 116.823 & deep alluvium \\
GSC & Goldstone & 35.303 & 116.808 & rock \\
PAS & Pasadena & 34.148 & 118.172 & rock \\
PFO & Pinyon Flats & 33.609 & 116.455 & rock \\
SVD & Seven Oaks Dam & 34.104 & 117.100 & rock \\
\hline
\end{tabular}




\section{Rupture Initiation}

Evidence from the strong-motion modeling indicates that the rupture initiation was rather subdued, reminiscent of delayed initial growth of the Loma Prieta earthquake (Wald et al., 1991). Most strong-motion accelerations show much larger secondary arrivals about $3 \mathrm{sec}$ after $P$-wave triggering. Further confirmation of this delay is seen in the similar delay to the onset of near-field energy seen on the TERRAscope horizontal velocity recordings (Dreger, 1994, Fig. 2) and from a delay in the arrival of significant energy seen on body waves at teleseismic distances (see later section). The consistency of the delay between the $P$-wave onset and that of significant energy at several strong-motion sites led Abercrombie and Mori (1994) to conclude that the nucleation of large slip must be within 1 to $4 \mathrm{~km}$ of the hypocenter.

From these observations, we choose to initiate the first time window $2.5 \mathrm{sec}$ after the hypocentral time (11:57:34.1). We thus chose to ignore the foreshock or rupture initiation, and we began modeling near the time of the first significant strong ground motion. We assume that the main rupture began at or near the network hypocenter location and then allow rupture to propagate out from that location. Again, this approach is consistent with our analysis of the teleseismic data, which also begin with the first significant rupture, as the initial rupture or foreshock was too small to be recorded teleseismically. Fortunately, the geodetic data provide an independent check on this assumption, since the slip determined by

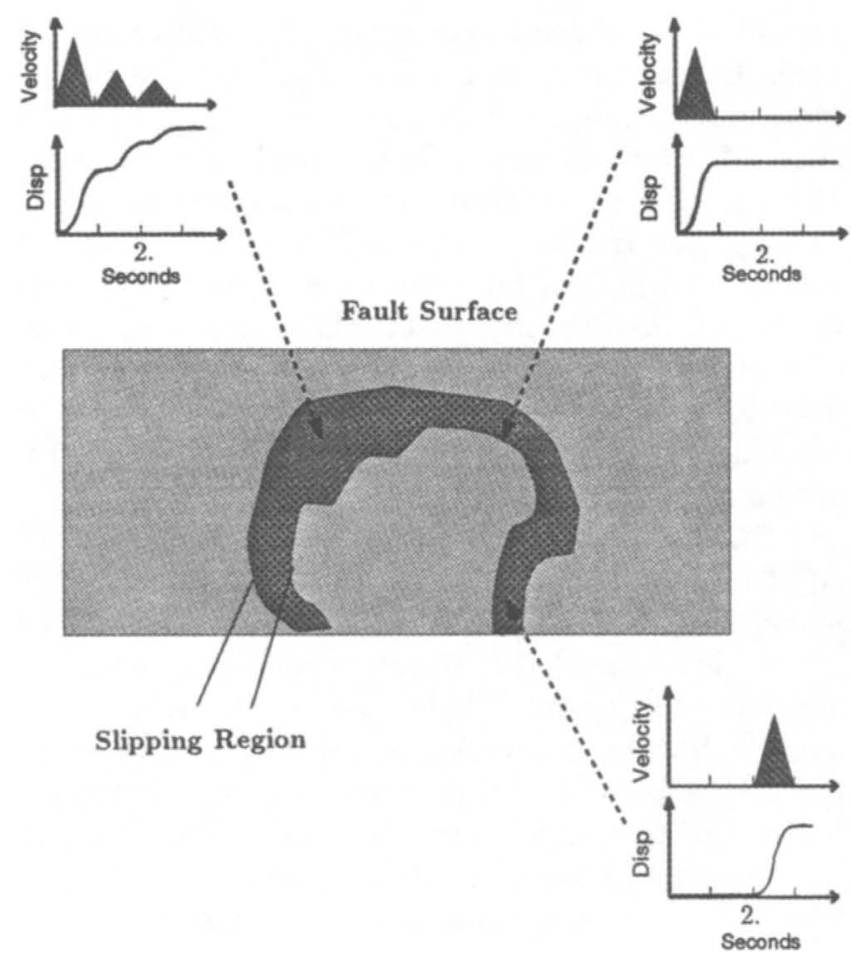

Figure 3. Schematic diagram illustrating the use of multiple time windows (see text for details). the static data is completely removed from timing assumptions.

It is not uncommon for the hypocenter determined from high-gain regional network data to represent a foreshock or an earlier stage of rupture not observed on other data sets. Wald et al. (1990) discuss the rupture process of the 1987 Superstition Hills earthquake and suggest that the network hypocenter represents an earlier foreshock and not the main rupture initiation. Further, Wald and Heaton (1992) found a 2-sec delay in the rupture of the 1989 Loma Prieta earthquake.

\section{Surface Offsets Constraints}

One noteworthy feature of the Landers earthquake was that although there were large measured surface offsets, no significant afterslip was observed (Sylvester, 1993). While it is conceivable that afterslip occurred only during the first hours after the mainshock, it seems more reasonable to assume that the surface offsets are co-seismic. Therefore, we used the surface offset data to constrain slip on the shallowest part of our rupture model. As will be discussed later, the surface offsets can be adequately modeled without assuming any afterslip.

The cumulative value of slip from all the minor mapped strands, projected to the main rupture trace as determined by Sieh et al. (1993), is used explicitly to constrain the shallowest fault slip. We average the measured surface slip along the 3-km length of each subfault (Fig. 2) and assign that value to the shallowest subfault element. Hence, the surface slip is inferred to be representative of slip to a depth of $2.5 \mathrm{~km}$. It is advantageous to incorporate this constraint because we know where and how much the surface slipped. This constraint can be judiciously fixed or eased, and in the results that follow, the shallow slip values were given sufficient freedom to vary roughly $\pm 50 \%$ from the assigned value.

The earliest models of the Landers surface offset (e.g., Kanamori et al., 1992) suggested a pronounced minima in the profile of slip along strike, separating two distinct lobes of slip. This feature is not pronounced in the more detailed slip estimates (Sieh et al., 1993). Rather, the surface slip can be characterized as sharply increasing north from the epicenter along the Johnson Valley fault, rather uniform slip past the step-over onto the Emerson fault; and a pronounced peak of slip along the Emerson/ Camp Rock strand (Fig. 2). The maximum surface slip, averaged over the 3-km-length subfaults, is about 6 and occurred about $5 \mathrm{~km}$ ( 2 subfaults) southeast of the strongmotion site LUC (Fig. 2).

Up to $20 \mathrm{~cm}$ of surface slip was mapped south of the epicenter along the Eureka Peak fault (Hart et al., 1993), but this slip most likely occurred during large, immediate aftershocks (Hough et al., 1994). For this reason, we consider the effect of this late slip on the permanent static displacements, but do not allow coseismic slip to occur on this fault. 


\section{Inversion Method}

A constrained, damped, linear least-squares inversion procedure is used to obtain the subfault dislocation values which give the best fit to the displacement waveforms and geodetic vectors. The inversion is constrained by requiring that the slip is everywhere positive. It is damped by minimizing the difference in dislocation values between adjacent subfaults (during each time window), and by minimizing the total amount of slip. These constraints have been previously discussed by Hartzell and Heaton (1983). For this study, we impose an additional constraint that the slip on the shallowest subfaults is equal to the observed surface slip, though the time dependence to reach that slip is determined in the inversion.

Solving for the strike-slip amplitude of slip on each subfault, given the strong-motion or teleseismic observations and subfault synthetic seismograms, is posed as an overdetermined system of linear equations,

$$
\mathbf{A x} \cong \mathbf{b},
$$

where $\mathbf{A}$ is the matrix of subfault synthetics, $\mathbf{x}$ is the solution vector consisting of subfault slip weights, and b is the data vector. The damping is included by appending a number of rows to the equations as follows:

$$
\left(\begin{array}{c}
\mathbf{C}_{d}^{-1} \mathbf{A} \\
\lambda_{1} \mathbf{S} \\
\lambda_{2} \mathbf{M} \\
\lambda_{3} \mathbf{F}
\end{array}\right) \mathbf{x} \cong\left(\begin{array}{c}
\mathbf{C}_{d}^{-1} \mathbf{b} \\
0 \\
0 \\
\mathbf{D}
\end{array}\right)
$$

Here $\mathbf{C}_{d}^{-1}$ is an a priori data covariance matrix which normalizes and weights the data, and $\mathbf{S}$ is a matrix of smoothing constraints which minimize the slip difference between adjacent subfaults $\left(x_{i}-x_{i+1}=0\right)$, both along strike and downdip. The term $\mathbf{M}$ is a matrix of minimizing constraints setting $x_{i}=0$. Matrix $\mathbf{F}$ forces the sum of all time windows for a subfault to equal a given dislocation value so that $\Sigma_{j=1}^{6} x_{i}\left(t w_{j}\right)=d_{i}$ for the shallowest subfaults, where $d_{i}$ is slip measured at the surface, and $t w_{j}$ represent the six time windows. Linear weights $\lambda_{1}, \lambda_{2}$, and $\lambda_{3}$ control the trade-off between satisfying these constraints and fitting the data.

In the case of the geodetic inversion alone, the number of data is smaller than the number of unknown slip values, and thus, the inversion is formally underdetermined. Although smoothing constraints make the inverse overdetermined, significantly more smoothing is needed for the geodetic data inversion than is needed for the strong-motion or teleseismic solutions. For the waveform observations, the number of data is increased greatly because each station's data is in the form of a time series. No slip minimization is needed in modeling the geodetic data alone since the Green's functions are sim- ple, and the non-negativity constraint is all that is required to damp the solution. In contrast, since the later portions of the synthetic Green's functions become less and less accurate, waveform inversions tend to map laterarriving phases back into the source, and thus, some degree of total slip minimization to avoid spurious slip contributions can be helpful. However, after many test inversions, we found that no slip minimization was necessary for modeling the Landers earthquake.

Though our inversion finds the optimal values for many parameters, many other important parameters are not explicitly inverted for-examples are the smoothing and minimization weights for each data set, rise time, rupture velocity values, and the assumed fault segmentation and geometry. In this analysis, numerous inversions were performed, and the models that are presented below represent features common to many iterations through the vast parameter space.

\section{Geodetic Inversion}

Since analysis of the static data for the slip distribution avoids any a priori assumptions about rupture propagation, we will discuss it first.

\section{Data}

The geodetic data available for the Landers earthquake consist of a number of trilateration and GPS measurements (for a summary, see Hudnut et al., 1994). The data were initially in the form of displacement vectors for GPS sites and line-length changes for trilateration stations. In this study, we chose to invert the station displacement vectors determined from reoccupation of GPS sites (M. Lisowski and J. Freymueller, written comm., 1993) and displacements determined for the trilateration sites by Murray et al. (1993) and M. Lisowski (written comm., 1993). Their trilateration site displacements were determined from variation of coordinate procedures, with constraints on rigid-body rotation provided by absolute displacements at GPS sites (Murray et al., 1993). The monument locations and displacements used in this procedure are shown in Figure 4.

The measurements span the time period after the 22 April 1992 Joshua Tree earthquake and immediately following the 28 June 1992 Landers event. Since this time span includes the $M_{W} 6.2 \mathrm{Big}$ Bear event and substantial aftershocks along the Eureka Peak fault, the effect of these fault dislocations must be considered when trying to infer the co-seismic slip which took place during the Landers rupture alone, even though they are relatively minor compared to the Landers signal. Rather than inverting for slip on the Big Bear and Eureka Peak fault segments (Fig. 4), we assume their rupture parameters based on previous studies, compute the predicted surface displacements, and remove that effect from the obser- 
vations. For the Big Bear segment, we used a fault length of $12 \mathrm{~km}$ striking $57^{\circ}$, a width of $12.5 \mathrm{~km}$ (starting at a depth of $2.5 \mathrm{~km}$ ), a uniform slip of about $115 \mathrm{~cm}$, and a total seismic moment of $0.52 \times 10^{26}$ dyne-cm. The Eureka Peak segment is assumed to have a length of 20 $\mathrm{km}$, a width of $12 \mathrm{~km}$ (breaking the surface), and a total seismic moment of $0.22 \times 10^{26}$ dyne-cm; the shallow slip ( 0 to $4 \mathrm{~km}$ ) is assumed to be $30 \mathrm{~cm}$, half as large as the $60-\mathrm{cm}$ slip assigned to the deeper portion of the fault (4 to $12 \mathrm{~km}$ ).

The observed displacement vectors, corrected for the Eureka Peak and Big Bear contributions, are displayed with solid arrows in Figure 4. With the exception of site WARR and other sites near the Eureka Peak and Big Bear

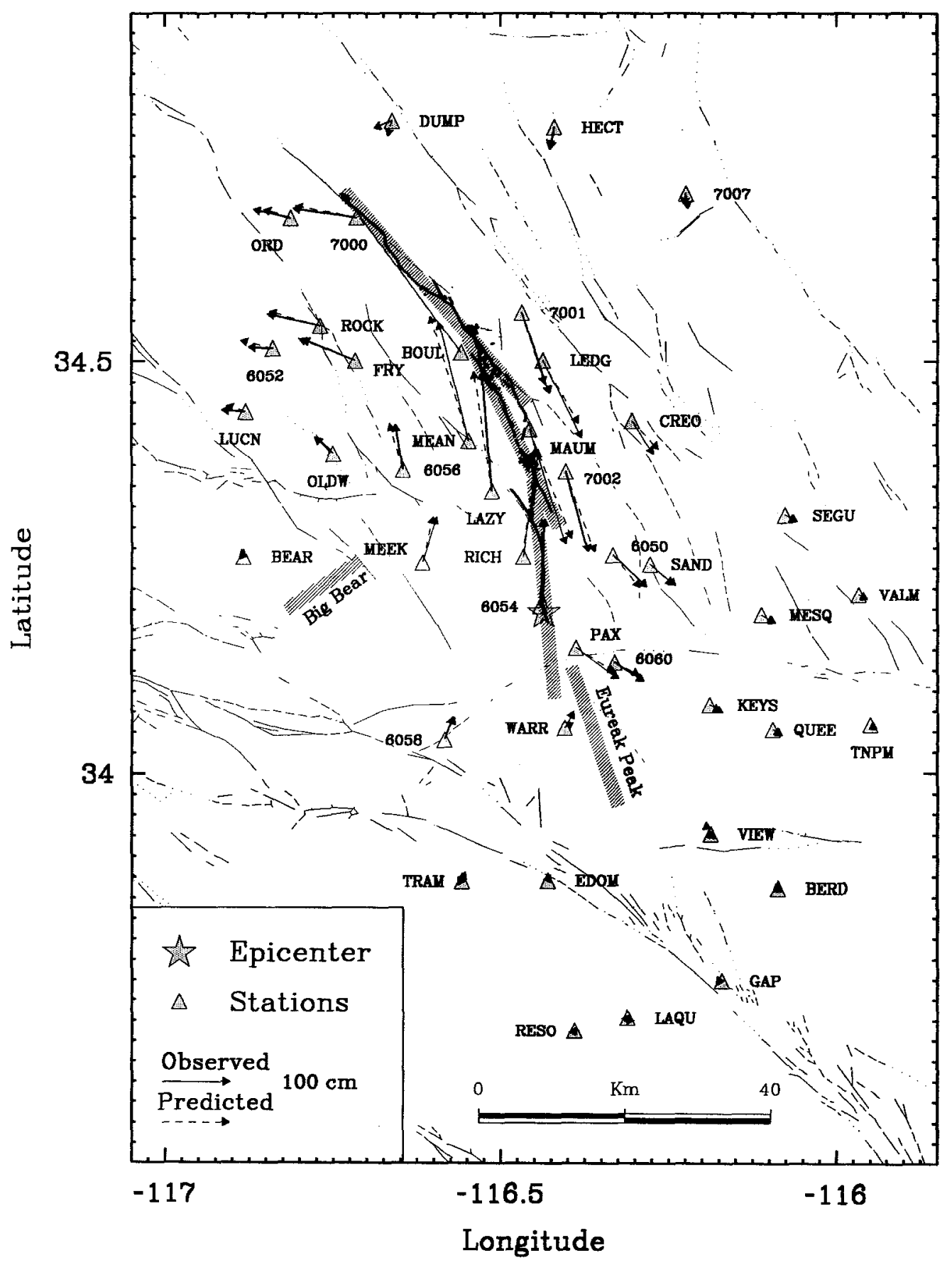

Figure 4. Location map of GPS and trilateration network stations (triangles) with relationship to model fault segments (hatchured lines). The observed (solid) and predicted (dashed) horizontal displacement vectors are presented with arrows, with the amplitude scaling as shown in the inset. Light lines represent a digitized version of major Quaternary faults of Jennings (1975). 
ruptures, the effect on the observed signals is nearly indistinguishable from the original observations.

\section{Modeling and Results}

The values of both linear weighting factors $\lambda_{1}$ and $\lambda_{2}$ [equation (2)] were determined from trial and error. No slip minimization was used. The shallowest elements were allowed to vary roughly 50\% from the assigned surface offset values as averaged along each shallow subfault (Fig. 2). The spatial distribution of slip obtained from inversion of only the geodetic data is given in Figure 5. An earlier initial inversion of a subset of the data (about half of the stations) yielded a slip distribution very similar to the final model shown in Figure 5. The full data set slightly tightened features that were originally broader as a function of depth. Accordingly, the geodetic static slip distribution is fairly robust along strike, but is less well resolved with depth.

The maximum strike slip at depth is over $6 \mathrm{~m}$ and is located on the Homestead Valley fault; the shallow peak slip shows a similar value on the Emerson fault.
The total seismic moment and seismic potency (slip $x$ area) as well as the separate fault contributions are summarized in Table 3. Variations in the depth extent of slip are apparent, with deep slip to at least $15 \mathrm{~km}$ along both the Landers and Homestead Valley faults. Offset is confined to shallower portions of the fault near the hypocenter, in the central Homestead Valley fault, and on the northern Emerson and Camp Rock faults, particularly toward the northwest terminus of surface rupture. In general, the slip measured at the fault surface does a poor job at predicting the average slip at depth. In particular, there is an offset of the maximum slip at depth relative to the peak surface slip, and the shallow slip along the northern Emerson and Camp Rock faults has no deep continuation.

In Figure 4, the displacement vectors predicted (dashed arrows) from the slip model given in Figure 5 are compared to the observed vectors (solid arrows). Considering the simplicity of the three-fault-segment approximation compared with the complexity of the surface offset, and the close proximity of many of the geo-
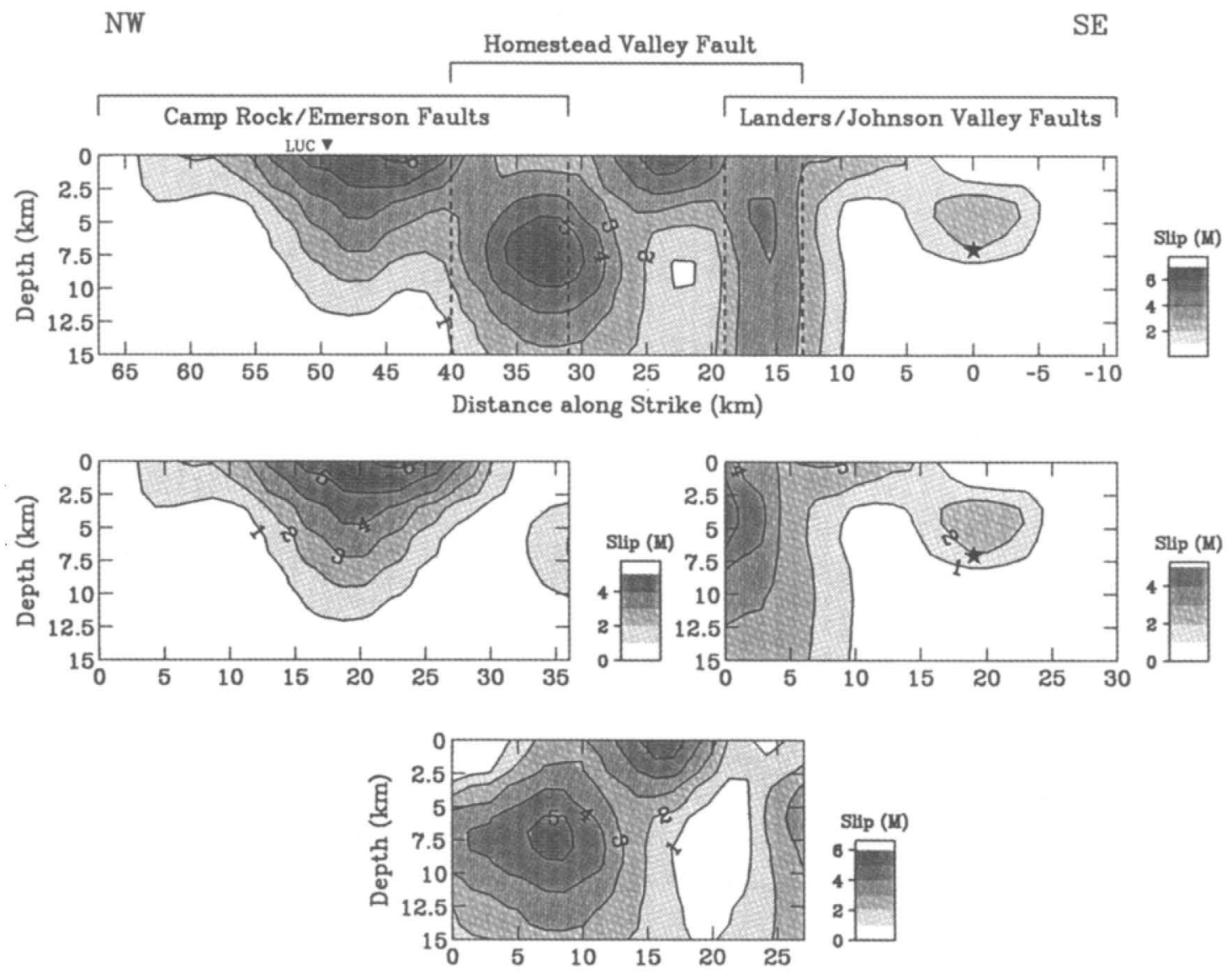

Figure 5. Cross section of the strike-slip distribution determined from modeling the geodetic data exclusively. The bottom three faults are the contributions to the complete fault model (top), with overlapping regions summed in the top model (within the vertical dashed lines). The contour interval is $1 \mathrm{~m}$, and the first contour given is $1 \mathrm{~m}$. The scale bar to the right of each fault shows the slip shading in meters. 
detic monuments to the fault trace, the overall static displacements are reasonably well fit.

\section{Teleseismic Inversion}

\section{Data}

The teleseismic station locations for the broadband data used in this study are listed in Table 4, and their azimuthal distributions with respect to the $P$ and $S H$ radiation patterns are shown in Figure 6. The three focal mechanisms represent the three different strikes of the model fault planes (Fig. 1).

These stations provide a variable azimuthal coverage of the source. Several other stations were available, but were not used, since they did not add significantly to the azimuthal coverage. Fortunately, however, almost all stations go through either a $P$ or $S H$ radiation node from one segment of the fault to the next (Fig. 6). This is caused by the change in strike from $355^{\circ}$ to $320^{\circ}$ over the extent of the rupture. These polarity changes produce unique waveform interference variations from station to station. The net effect is an enhanced sensitivity of teleseismic waveforms to distribution of slip along strike relative to uniform-strike events, since both correct timing (distance along strike) and strike azimuth are required to fit the data. This change in strike is manifest in the vari- ability of the $P$ and $S H$ displacement waveforms shown in Figure 7. The amplitudes are normalized to the peak value at each station. The instrument responses have been deconvolved from the original recordings to obtain ground displacements (in microns), and the data are bandpassed from 0.33 to $0.01 \mathrm{~Hz}$.

The first dashed vertical line in Figure 7 is the predicted body wave arrival time based on IASPEI91 (Kennett and Engdahl, 1991) travel times and the hypocentral parameters. At most stations, we see an approximately 3-sec delay (the second dotted line) of the first significant observed arrivals. This delay is in agreement with the near-field observations which indicated a similar delay of significant rupture relative to the hypocentral origin time. On the stations with the greatest signal-to-noise ratios (e.g., COL, HRV, MAJ, OBN, TOL), it is clear that there is very little energy arriving within the 3 -sec window after the expected arrival and prior to the delayed arrival, placing an upper bound on the energy radiated during the initial $3 \mathrm{sec}$ of rupture.

\section{Modeling and Results}

For the teleseismic data, we modeled the first $60 \mathrm{sec}$ of both the $P$ and $S H$ wavetrains. We began the rupture $2.5 \mathrm{sec}$ after the expected travel time, and allowed minor corrections for travel-time variations at select stations ( $P$ and $S H$ delays are given in Table 4). The corrections

Table 3

Fault Model Parameters

\begin{tabular}{lcccc}
\hline \multicolumn{1}{c}{ Model } & Moment* & Mol $^{\dagger}$ & Mo2 & Mo3 \\
\hline Geodetic & $0.69(2.29)$ & $0.17(0.56)$ & $0.32(1.03)$ & $0.20(0.70)$ \\
Teleseismic & $0.73(2.53)$ & $0.21(0.72)$ & $0.28(0.94)$ & $0.24(0.87)$ \\
Strong Motion & $0.74(2.60)$ & $0.15(0.56)$ & $0.28(0.97)$ & $0.31(1.04)$ \\
Combined & $0.77(2.74)$ & $0.20(0.71)$ & $0.36(1.07)$ & $0.21(0.83)$ \\
\hline
\end{tabular}

*( $\times 10^{27}$ dyne-cm).

Mo1, Mo2, and Mo3 refer to the Johnson Valley/Landers, Homestead Valley, and Camprock/ Emerson fault moment contributions, respectively. The values in parentheses are seismic potency (slip times area) in $\mathrm{km}^{3}$.

Table 4

Teleseismic Stations

\begin{tabular}{lcrrcc}
\hline \multicolumn{1}{c}{ Station } & Delta (9) & Backazimuth & Azimuth & $P$ Delay (sec) & SH Delay (sec) \\
\hline COL & 36.1 & 133.0 & 337.9 & -1.0 & -4.0 \\
GUMO & 89.5 & 55.0 & 286.0 & 3.0 & 3.0 \\
HRV & 35.7 & 271.8 & 63.0 & -3.0 & -5.0 \\
KIP & 38.7 & 61.7 & 261.8 & 0.0 & - \\
KONO & 76.5 & 316.4 & 25.0 & 0.0 & 0.0 \\
MAJO & 81.1 & 54.0 & 308.2 & 0.0 & 0.0 \\
NNA & 59.4 & 322.1 & 133.6 & 0.0 & 0.0 \\
OBN & 87.7 & 337.9 & 15.1 & -3.0 & -4.0 \\
RAR & 68.8 & 37.6 & 223.4 & -4.0 & -6.0 \\
RPN & 61.4 & 353.3 & 172.8 & -2.0 & -5.0 \\
TOL & 83.4 & 309.5 & 45.7 & 0.0 & 0.0 \\
\hline
\end{tabular}


were chosen based on a careful examination of the velocity waveforms, since the initial arrival is more impulsive in velocity than in displacement. It may be possible to improve the resolving power of the teleseismic data by modeling velocity with empirical time delays rather than displacement waveforms. This would emphasize higher-frequency information.

The apparent delay in $S H$ arrivals at NNA and RAR is expected considering the initial strike of the Joshua Tree fault. As shown in Figure 6, both stations are near $S H$ radiation nodes, and they do not show significant arrivals until later in the rupture when the strike turns to the northwest, altering their radiation pattern away from near-nodal. Likewise, the $P$ wave at KIP is initially nodal because of the strike of the Johnson Valley fault, then becomes compressional for the Homestead Valley and Camprock faults. Others stations change phase polarities during the rupture. The COL $P$ wave, for example, begins compressional on the Johnson Valley fault and reverses polarity with the change of strike to the Homestead Valley fault. It is exactly this type of feature that gives the teleseismic data resolving power to locate slip on each fault segment.

Figure 8 displays a comparison of the teleseismic body-wave displacement observations (solid lines) with the synthetics (dashed lines) for the teleseismic dislocation model. Observed amplitudes are given to the right of each trace in microns, and all traces are displayed with a common amplitude scale. As is the case for other pure strike-slip earthquakes in southern California, the higher-frequency details of the body waveforms are difficult to model. However, the overall waveforms are well modeled. A cross section of the strike-slip distribution determined from modeling only teleseismic body waves is presented in Figure 9. Again, the contour interval is $1 \mathrm{~m}$. Many of the general features of the slip distribution are in agreement with the geodetic dislocations (Fig. 5, Table 2), both in amplitude and location of slip. Again, only shallow slip is found along the northern Emerson and Camp Rock faults; the greatest slip is deep and south of the surface maximum; and most of the slip in the hypocentral region is shallow. However, in the teleseismic model, the peak slip along the Homestead Valley fault is shifted about $3 \mathrm{~km}$ northwestward compared to the geodetic model, and more slip is attributed to the southernmost Homestead Valley fault.

\section{Strong-Motion Inversion}

\section{Data}

The Landers earthquake is the largest event recorded in the United States with an extensive set of strong-motion records (Earthquake Engineering Research Institute, 1992). The displacement ground motions are especially long period (dominated by 3 to $10 \mathrm{sec}$ ) and longer in duration relative to other well recorded events. Clear northward directivity in the amplitudes of the waveforms is apparent, especially in longer-period displacement records. Figure 10 shows the displacement waveforms

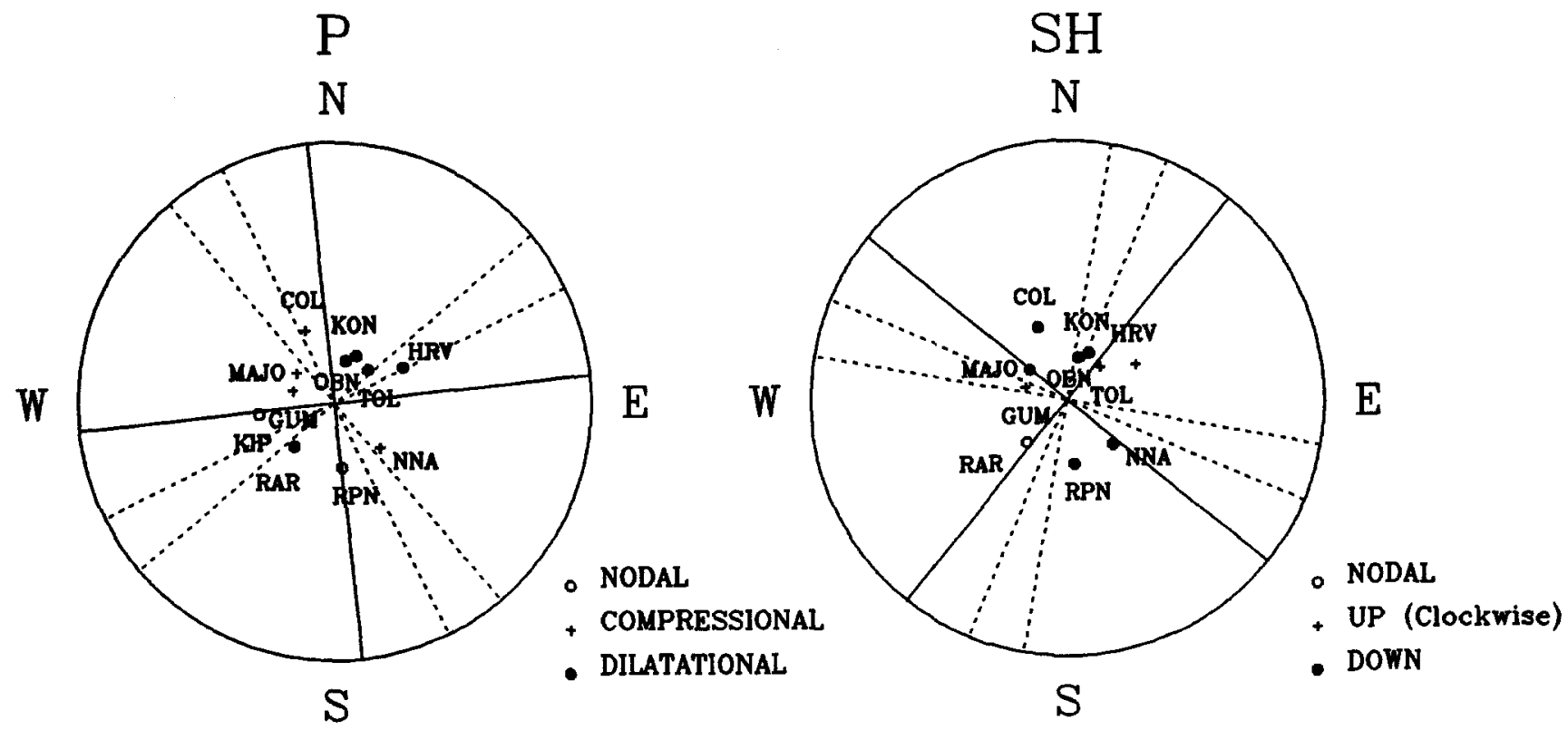

Figure 6. Vertical strike-slip $P$ and $S H$ radiation patterns for the three model fault segments. The solid line represents the Johnson Valley/Landers segment (strike $355^{\circ}$ ), and the dashed lines depict the Homestead Valley fault (strike $334^{\circ}$ ) and the Emerson/Camp Rock segment (strike $320^{\circ}$ ). Station locations are plotted according to azimuth and take-off angle. 
for select stations in map view with their amplitudes on a common scale. The amplitude at YRM is nearly five times larger than at DHS, even though they are at comparable distances from the nearest fault or surface offset (a distance parameter commonly used in earthquake engineering). Amplitudes to the west (HSP) and east (AMB) are smaller. These observations can be mostly attributed to the unilateral rupture northward from the epicenter. This prominent northward directivity helps explain why seismicity was triggered at large distances to the north, but not to the south (Hill et al., 1993), although the exact triggering mechanism is not well understood.

In our analysis, we use strong-motion accelerograms from the Caltech (TERRAscope), the CDMG (Shakal et $a l ., 1992$ ), the USGS, and Southern California Edison. Table 2 lists the station abbreviations and locations, as well as site surface conditions. The distribution of groundmotion stations is displayed in Figure 10. Most of the records are standard SMA-1 analog recordings digitized by the CDMG. Those from TERRAscope and the two from the USGS (EWC and MVB) are force-balance accelerometer (FBA) digital records. The Lucerne Valley record (LUC) was made available by Southern California Edi-

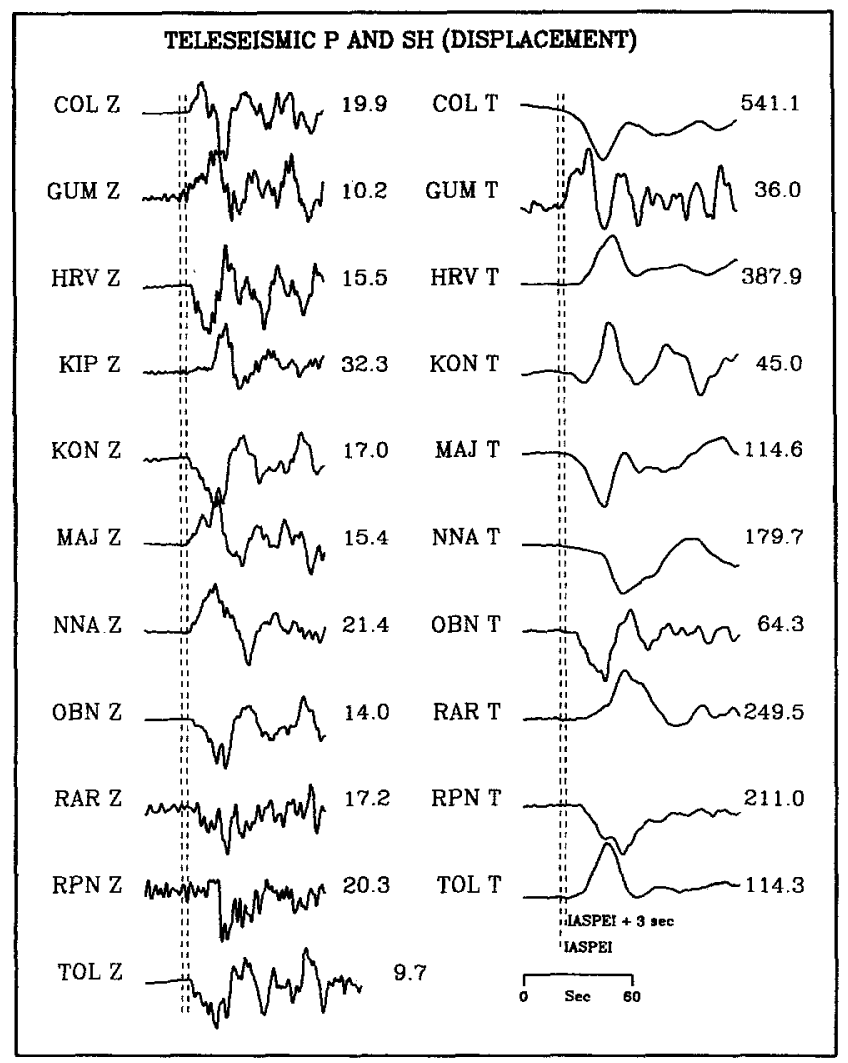

Figure 7. Observed teleseismic body wave displacement records shown with predicted IASPEI91 travel times (first dashed line) along with reference arrival times $3 \mathrm{sec}$ later (second dashed line) based on the delay in rupture. Amplitudes are given in microns. son and is of the less-common SMA-2 type, which is written on analog FM tape. The Hesperia and Big Bear SMA-1 records were scanned and digitized by the authors.

When the trigger time is available, synthetic and observed waveforms were aligned in absolute time, and no corrections were made for static station delays. We aligned those stations without absolute time (YRM and LUC) by performing a preliminary inversion with those stations having absolute time weighted heavily, and those stations without absolute time downweighted, effectively removing them from the inversion. Using the preliminary inversion results, synthetic waveforms were calculated for those stations without timing, and the best alignment was estimated by comparing synthetic and observed waveforms. These timing values were not further adjusted.

The accelerograms are bandpass-filtered between 0.077 and $0.5 \mathrm{~Hz}(13$ and $2.0 \mathrm{sec})$ with a zero-phase, third-order Butterworth filter and then doubly integrated to obtain displacements. This bandpass was chosen to avoid long-period integration noise and to avoid inadequacies of the theoretical Green's functions at higher frequencies. Our inability to adequately estimate strongmotion Green's functions at frequencies higher than 0.5 $\mathrm{Hz}$ is limited by our knowledge of the crustal velocity structure, and by the lack of absolute timing at some strong motion sites. The use of displacements rather than velocity or acceleration further emphasizes longer-period characteristics of the strong motions. With better analyses of the local velocity structure, both through traveltime tomography and aftershock waveform studies, this high-frequency limit may be extended to a few Hertz. This would allow velocity waveforms, rather than displacements, to be modeled.

The Lucerne Valley station (LUC) was recorded on an SMA-2 accelerograph. The SMA-2 response has marked fall-off beginning at about 2 to $3 \mathrm{sec}$ (Dullien, 1972), and at the dominant frequency in the displacement waveform (4-sec period), the instrument response is approximately $70 \%$ of the true amplitude. For this reason, we have scaled the amplitudes at station LUC by a factor of 1.43 for both velocity and displacement in order to approximate the true amplitude. This approximation is in agreement with the displacement and velocity amplitudes corrected for the instrument response at the Caltech earthquake engineering laboratory (B. Iwan, written comm., 1993). The LUC observations are quite important because the station is close to the rupture and because there are no other stations in the vicinity (Fig. 1). Thus, we have chosen to model both the velocity and displacement time histories, thereby effectively doubling the importance of this station in the inversion.

\section{Modeling and Results}

We modeled between 25 and $50 \mathrm{sec}$ of the strongmotion records (Fig. 11), depending on the duration at 
individual stations. We do not rotate the stations to fault normal and parallel, since for most stations, the extended fault length makes rotation ambiguous. In initial modeling, we employed the vertical as well as the horizontal components, but we found the vertical records were not as well modeled. Since the vertical components are dominated by $P$ waves, they are higher in frequency content than the horizontal components and show more indications of phase conversions and propagation complexity. For this reason, vertical strong motions are not considered in this study. The use of the vertical components may become feasible with an improved understanding of regional wave propagation and velocity structure. Unfortunately, our layered $1 \mathrm{D}$ velocity structure appears to be insufficient to adequately model these motions.

A comparison of the strong-motion displacement observations (solid lines) and synthetics (dashed lines) for the strong-motion dislocation model is given in Figure 11. Observed amplitudes are given to the right of each trace in centimeters, and all have a common scale. The ground motions at station LUC (Lucerne Valley) are presented in both velocity (LUCVW, LUCVN) and displacement (LUCDW, LUCDN), with the velocity amplitudes in centimeters per second. The overall waveforms, both in amplitude and phase, are very well matched by the synthetic ground motions at all stations.

The strike-slip distribution determined from modeling only strong-motion data alone is given in Figure 12. Again, most of the main dislocation features are consistent with earlier models (Figs. 5 and 9). By examining the slip on the three fault contributions (Fig. 5, middle and bottom) to the total slip (Fig. 5, top), it is apparent how the slip is transferred from one segment to the next as rupture propagates northwestward along the length of the fault. As slip at the intersection of the Landers and Homestead Valley faults terminates, slip is taken up on the Homestead Valley fault. Likewise, slip increases abruptly along the southern Emerson fault as it diminishes on the northern Homestead Valley fault. This is the first time that apparent transfer of slip during an earthquake rupture has been resolvable.

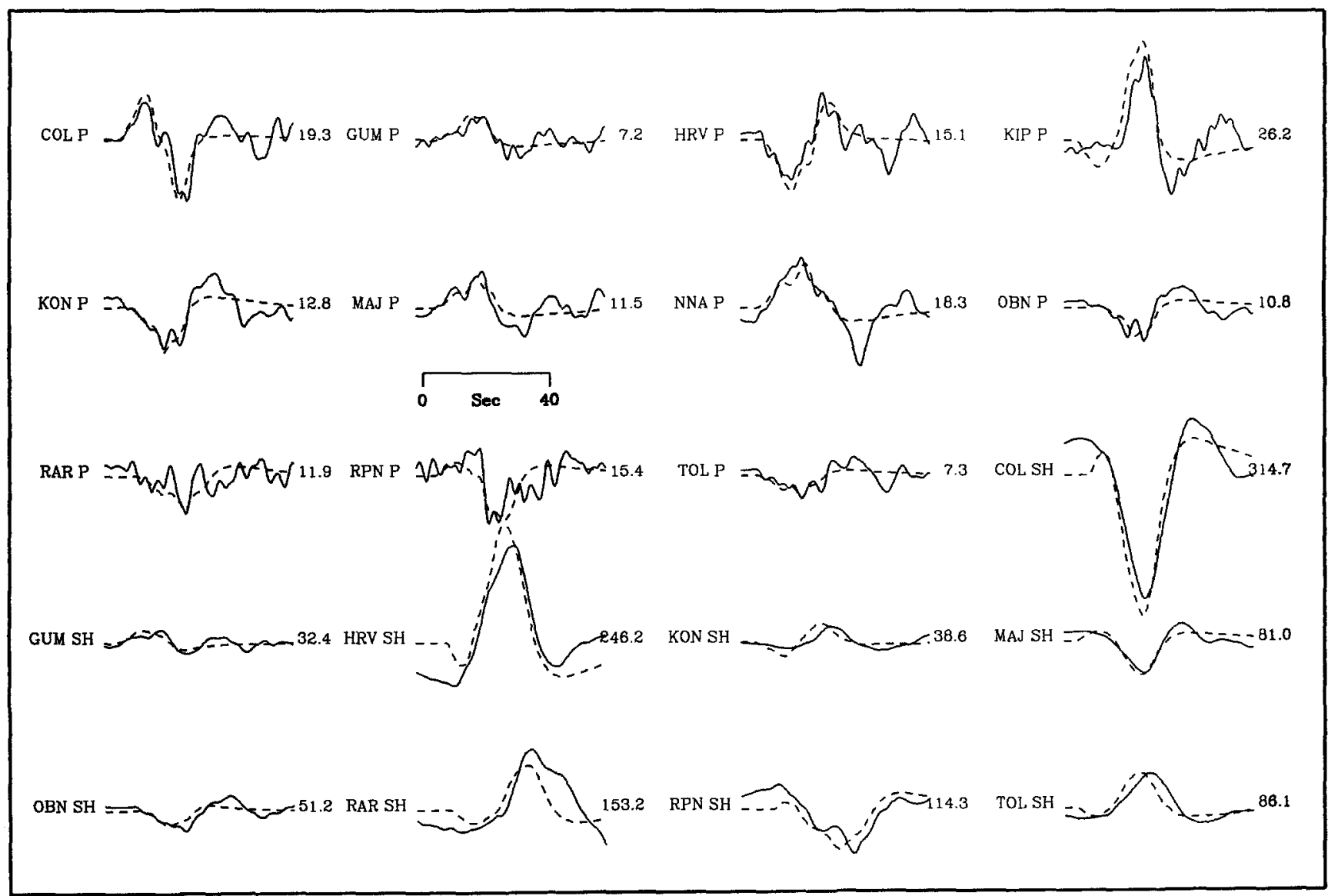

Figure 8. Bandpass-filtered $(0.33$ to $0.01 \mathrm{~Hz})$ teleseismic body-wave displacement observations (solid lines) and synthetics (dashed lines) for the teleseismic dislocation model presented in Figure 9. Observed amplitudes are given to the right of each trace in microns. All $P$ waves are scaled to a common value as are all $S H$ waves, with $P$ waves scaled a factor of 8 times larger. 


\section{Combined Inversion}

We now present an inversion with all of the data sets combined. Since the fault model parameterization and inversion remained unchanged for the variety of data sets, the combined inversion is a natural extension of the prior inversions. Although the number of unknowns remains fixed, the total number of data is greatly increased. The main difficulty encountered was determining the relative weighting factors for each data set, so that each would be equally represented in joint inversion. This was accomplished initially by estimating the total weight of each normalized data set based on the relative amplitudes and the total number of data points. We then perturbed this estimate on a trial-and-error basis to insure that the fit to any one data set was not selectively degraded.

The strike-slip distribution determined from modeling the combined data sets is given in Figure 13. For direct comparison, all the dislocation models are summarized in Figure 14. The total slip and seismic moment for the combined model are slightly larger for the combined inversion (Table 3). As expected, most aspects of the combined inversion slip model are similar to earlier, single-data-set models. This includes the deep slip gap located 19 to $25 \mathrm{~km}$ along strike, and the shallowing of slip near both ends of the rupture. Overall, the combined model slip pattern is most similar to the geodetic model. In order to fit the geodetic data, the pattern of slip must be correct. Conversely, matching the waveform data can be achieved by varying both the slip location and timing. In other words, it is easier to fit the waveform data with the geodetic slip by determining the best timing associated with a relatively fixed location of slip than it is to fit the geodetic data with the slip pattern determined from the waveforms alone.

Visually, it is easy to appreciate which features in the combined dislocation model can be attributed to individual data sets. For example, the deep slip between 14 and $19 \mathrm{~km}$ along strike can, in the teleseismic model, be shallowed without degrading the teleseismic waveform fits; likewise, the strong-motion data allow deeper slip in the same location. In contrast, deep slip in both the teleseismic model and strong-motion models at 25 to $40 \mathrm{~km}$ along strike must be retained, but the geodetic slip can readily be pushed deeper in that region without sacrificing the data fit.
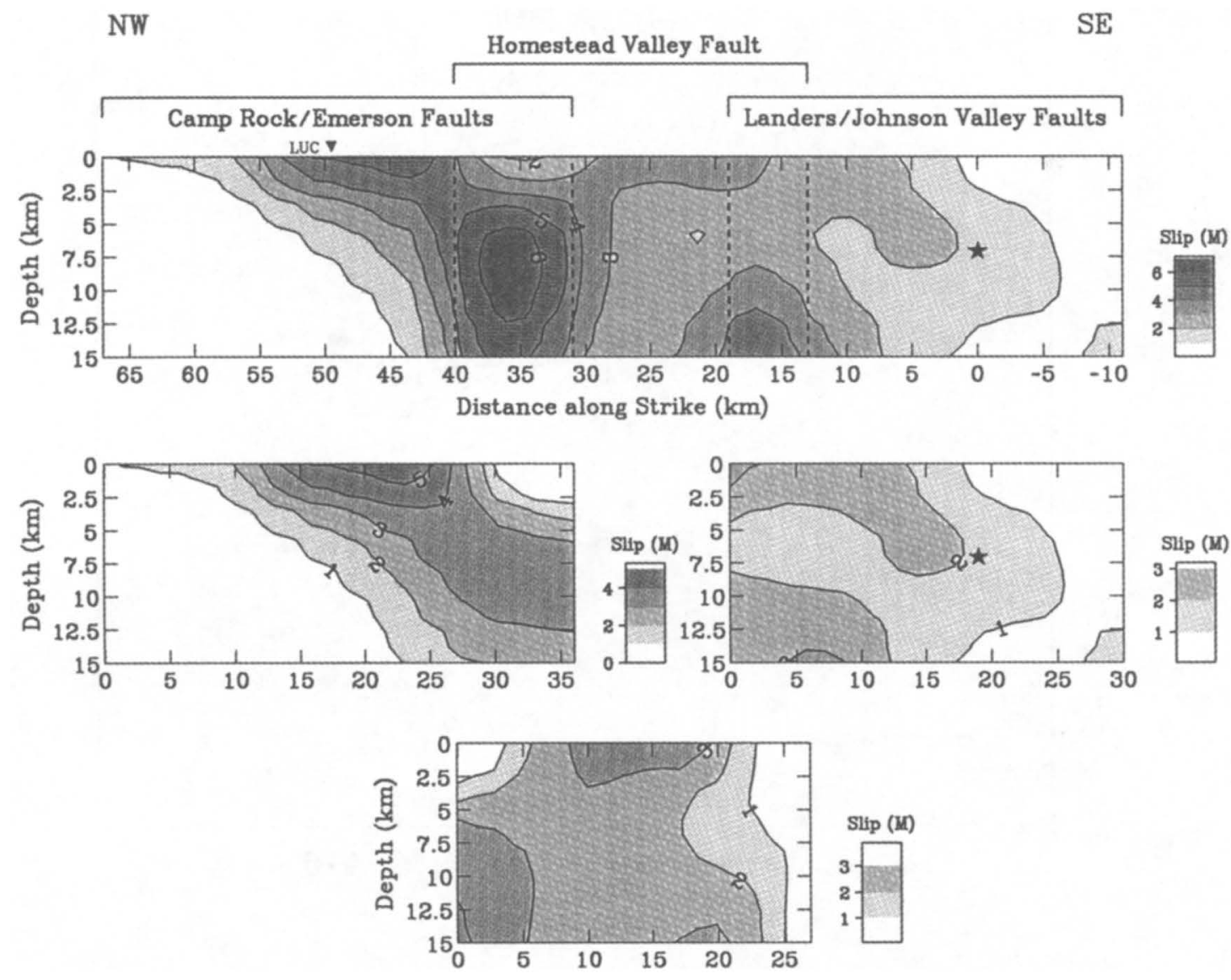

Figure 9. Cross section of the strike-slip distribution determined from modeling teleseismic body waves exclusively. The contour interval is $1 \mathrm{~m}$, and the first contour given is $1 \mathrm{~m}$. The scale bar to the right of each fault shows the slip shading in meters. 
We expected the total misfit for each data set to increase in the joint inversion since the number of unknown slip values remained unchanged while the number of data was greatly increased. Fortunately, there is little degeneration of the fit to the displacement vectors or the waveforms. Furthermore, only minor alterations to the slip distributions from the inversions of the in- dependent data sets were necessary to fit the entire data set.

By comparing the individual and combined model predictions, we found the total root-mean square error for the strong-motion, teleseismic, and geodetic data increased by 13,17 , and $12 \%$, respectively. However, the waveform and displacement vector fits are not as af-

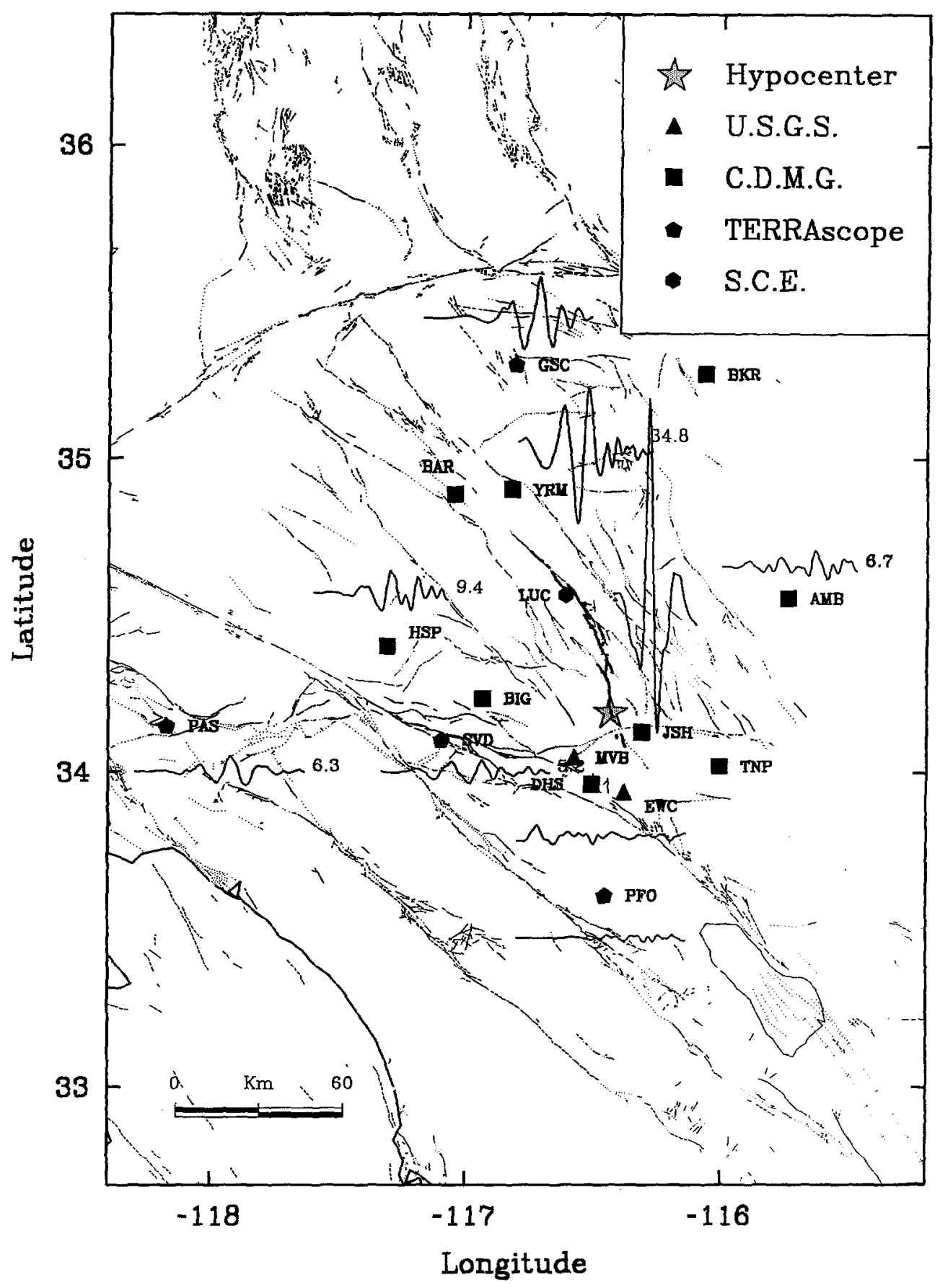

Figure 10. Location map displaying USGS (triangles) and CDMG (squares), TERRAscope (pentagons), and Southern California Edison (octagon) strong-motion stations used in this study. Shown next to selected stations are the observed displacement waveforms plotted on a common time and amplitude scale. The epicenter is marked by a star. The Landers surface slip is shown with thick lines. 
fected as the error might suggest. In fact, most of the error is in the form of slight overall amplitude over- or underpredictions since there are minor differences in the total slip from one data set to the next. The combined model must find the best average total slip, at the expense of any one data set.

\section{Discussion}

\section{Rupture Evolution}

With the final distribution of slip determined from the combined inversion presented, we now address the temporal evolution of the Landers rupture. While this can be done with the strong-motion or teleseismic solutions alone, we reserved the detailed analysis for the solution known to be the most consistent with all data sets. We have examined the temporal evolution of the two waveform models individually, and the results are similar to those shown below.

We display the individual time-window contribu- tions for the model from the combined data sets (Fig. 13) in Figure 15. The time at the right of each window gives its duration with respect to the rupture initiation ( $2.5 \mathrm{sec}$ after the hypocentral time). The contour interval is now $0.5 \mathrm{~m}$. If slip occurs on the same portion of the fault in multiple time windows, then the slip duration is longer (and/or more complex) and can be determined from the number of windows contributing. For example, slip near 30 to $35 \mathrm{~km}$ along strike at mid-depths consumed the first four time windows, so the duration was on the order of $4 \mathrm{sec}$. Since the total slip was over $7 \mathrm{~m}$ at this point, the particle velocity was approximately 1 $\mathrm{m} / \mathrm{sec}$. In general though, the local slip durations are short, less than $2.0 \mathrm{sec}$ for most of the rupture, but they are up to $4.0 \mathrm{sec}$ long in the regions of maximum slip, particularly for the shallow slip peak at about 40 to 50 $\mathrm{km}$ along strike.

Figure 15 also indicates those regions that slipped later or earlier than they would have given a constant rupture velocity. For example, on the Johnson Valley/ Landers segment, deep slip occurred in the first time

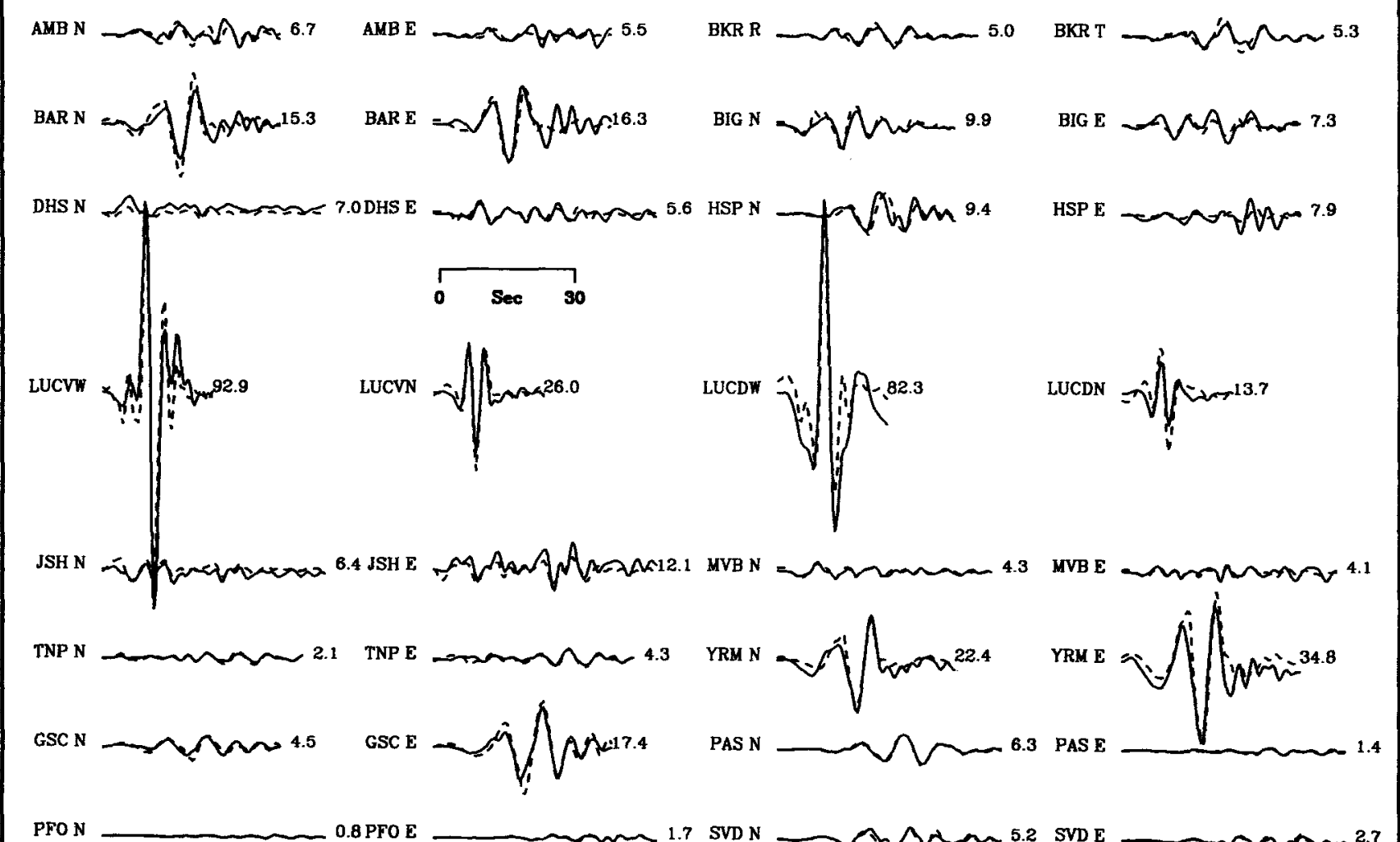

Figure 11. Strong-motion displacement observations (solid lines) and synthetics (dashed lines) for the strong-motion dislocation model. Observed amplitudes are given to the right of each trace in centimeter, and all have a common scale. For station LUC (Lucerne Valley), both velocity (LUCVW, LUCVN) and displacement (LUCDW, LUCDN) data and synthetics are presented, with the velocity amplitudes in $\mathrm{cm} / \mathrm{sec}$. 
window. However, shallow slip was delayed until the second time window. This represents a decrease in the rupture velocity as the rupture proceeds though the shallow fault region, from about $2.7 \mathrm{~km} / \mathrm{sec}$ to less than about $2 \mathrm{~km} / \mathrm{sec}$. Similar observations can be made along most of the fault length. Note that this decrease in rupture velocity for the shallow regions is not an a priori constraint, but, rather, comes out of the inversion by introducing multiple time windows. Such a decrease in the rupture velocity as slip shallows is expected if the rupture velocity decreases in proportion to the shear-wave velocity as the rupture extends to the surface.

Multiple time windows allow variations in rupture velocity and slip duration as a function of fault position. Although multiple time windows add greatly to the number of unknown parameters, nearly half of the time windows end up having no slip as a result of the inversion (Fig. 15). Thus, the added degrees of freedom do not contribute unnecessarily to the solution, nor do they add spurious complexity to the rupture model. Further, the major features of the final slip pattern (Fig. 13) are independent of the freedom allowed by the multiple time windows; they are most similar to the geodetic slip model in which we did not employ time windows.

We can easily convert our maps of slip in time windows that are moving with the rupture front (Fig. 15) to a set of maps of the slip velocity as a function of absolute time. Figure 16 depicts the slipping portion of the fault and the amount of slip during 1-sec "slices" in time; hence, the image can be thought of as slip velocity. For each time slice, the time duration after rupture initiation is given. Again, the contour interval is $0.5 \mathrm{~m}$.

Several observations are notable. As mentioned above, shallow slip usually lags slightly behind slip at depth, suggesting a slower shallow rupture velocity. And, although the rupture propagates at an average constant velocity of $2.7 \mathrm{~km} / \mathrm{sec}$ over the length of the rupture (a distance of roughly $60 \mathrm{~km}$ in $22 \mathrm{sec}$ ), there are indications of significant local variations.

Rupture is slowed and delayed along the Landers fault (time slices 6 to $9 \mathrm{sec}, 12$ to $18 \mathrm{~km}$ ). Just beyond this point, on the southern Homestead Valley fault, it appears that the rupture almost ended, but in an erratic fashion, began to accelerate across the central Home-

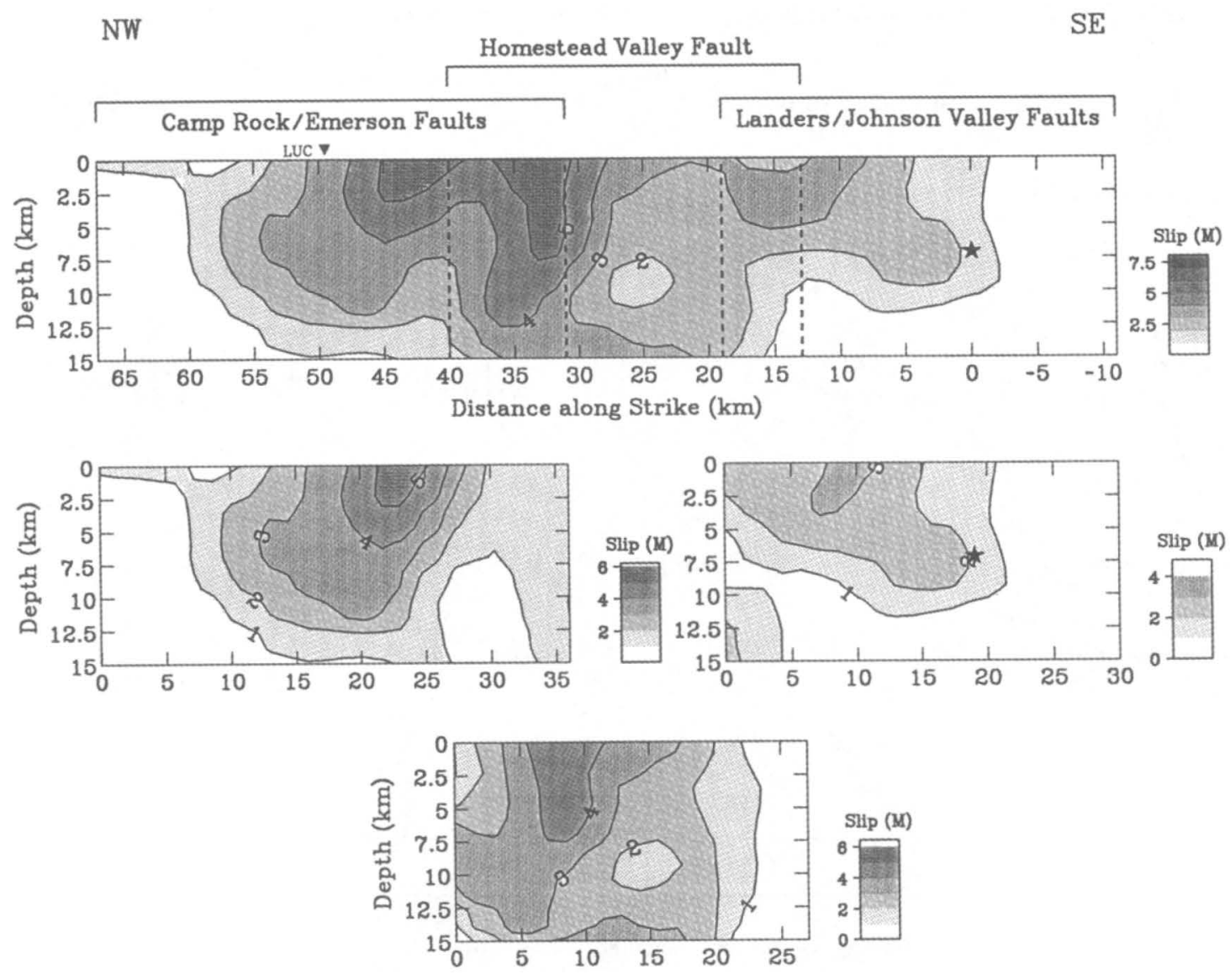

Figure 12. Cross section of the strike-slip distribution determined from modeling only strong-motion data. The contour interval is $1 \mathrm{~m}$, and the first contour given is $1 \mathrm{~m}$. The scale bar to the right of each fault shows the slip shading in meters. 
stead Valley fault and continue onward (time slices 9 to $12 \mathrm{sec}, 22$ to $32 \mathrm{~km}$ ). It again slowed on the northern Homestead Valley fault (time slices 12 to $16 \mathrm{sec}, 36$ to $40 \mathrm{~km}$ ) before jumping to the Emerson Fault (time slices 17 to $19 \mathrm{sec}, 44$ to $50 \mathrm{~km}$ ). Finally, the rupture trickled out on the shallow Emerson and Camp Rock faults (time slices 21 to $23 \mathrm{sec}, 50$ to $60 \mathrm{~km}$ ). For reference, lines of constant rupture velocity of the leading edge of slip are given for selected regions which exhibit roughly uniform rupture velocities. A slowing of the rupture front as it nears a fault step-over, followed by an acceleration, is intuitively appealing as corresponding to a large stress buildup near the step-over and rapid release as the stepover barrier is overcome.

We can also interpret these observations in light of recent finite-difference analyses of the dynamics of fault interactions by Harris and Day (1993). They found that dilational steps (as are the Landers step-overs) delay the rupture, with larger steps causing longer delays. If we consider the decreasing rupture velocity within the stepovers, there are time delays of a few seconds from the time of the arrival of the rupture front at the step-overs and the time rupture continues onward (Fig. 16). Though the geometry and aftershock seismicity within the Landers step-overs suggest that they are continuous at depth (Hauksson, 1993), and Harris and Day modeled unconnected fault steps (and specifically caution that their conclusions might change in such a case), these delays are consistent with their general results.

Curiously, at both step-overs, the rupture apparently propagates southeastward along the abandoned fault segments that are southeast of the actual fault intersections: at the southern step-over (time slice 11 to $12 \mathrm{sec}$ ), slip propagates southward along the southernmost Homestead Valley fault, and the step-over to the Emerson fault is accompanied by an apparent rerupturing of the northernmost Homestead Valley fault (time slice 18 to $19 \mathrm{sec}$ ). More likely, the latter represents rupture southeastward along the southern Emerson fault (Fig. 1) as the main rupture continues northwestward along the northern Emerson and Camp Rock faults. However, it is difficult to resolve whether slip is actually on the southernmost Emerson fault or northernmost Homestead Valley fault because of the proximity and similar strikes of the overlapping segments. Since rupture is continuing northwestward simultaneously with the southward-propagat-
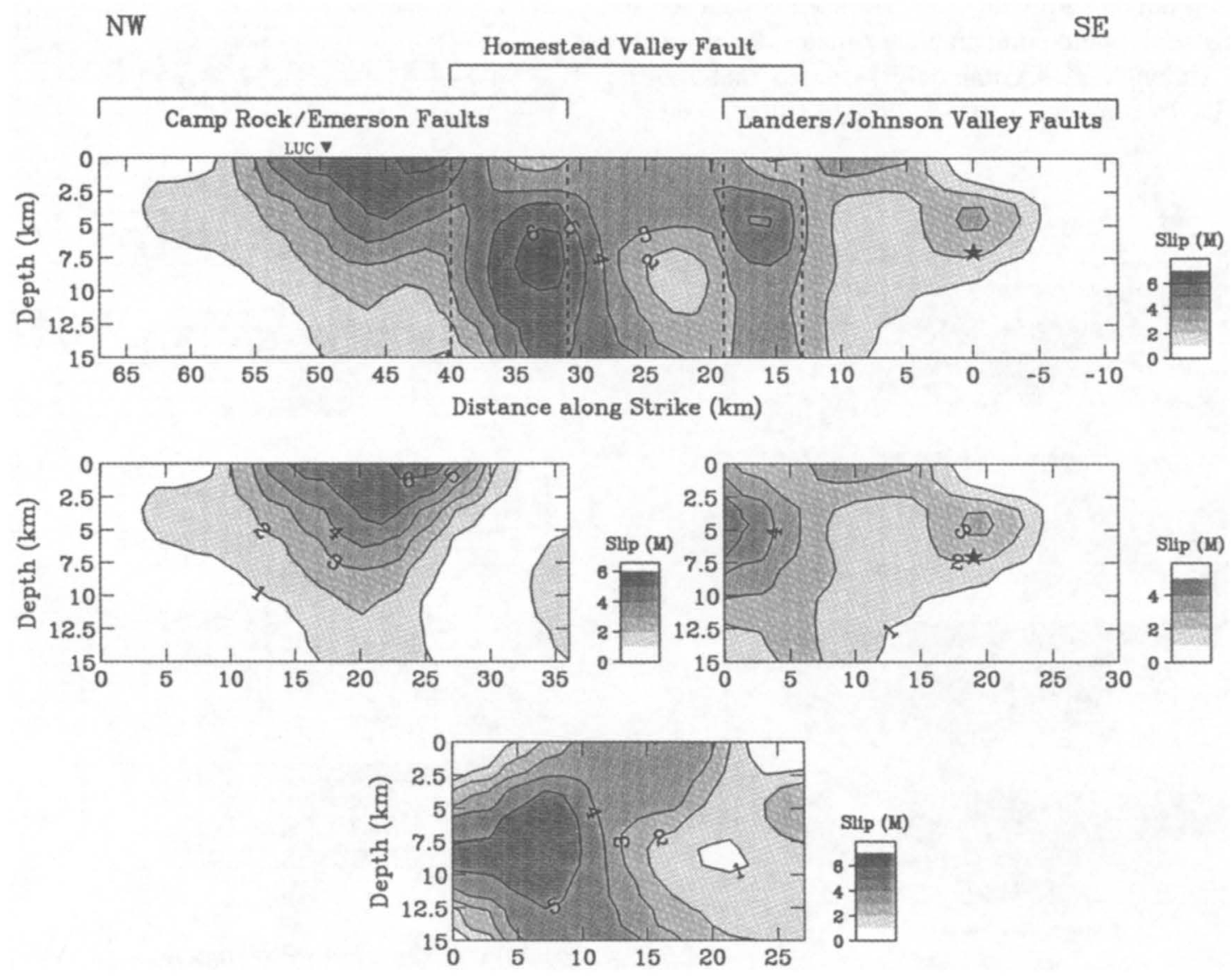

Figure 13. Cross section of the strike-slip distribution determined from modeling all data sets combined. The contour interval is $1 \mathrm{~m}$; the first contour given is $1 \mathrm{~m}$. 
ing rupture in question, energy radiated from both regions interferes at many stations, which serves to further complicate the interpretation of faulting in this region.

\section{Seismic Moment Estimates}

Total slip estimates from teleseismic broadband body wave, geodetic, and strong-motion data sets yield seismic moments within the range of 0.7 to $0.8 \times 10^{27}$ dyne$\mathrm{cm}\left(M_{W} 7.2\right)$. The consistency in the total slip estimates for each data set gives us some confidence in our seismic moment value. This value is in accord with previous estimates of $0.8 \times 10^{27}$ dyne-cm from empirical deconvolution of the Pasadena TERRAscope strong-motion channels and a value of $0.8 \times 10^{27}$ dyne-cm from the inversion of broadband body waves (Kanamori et al., 1992 ) as well as a geological estimate of $0.90 \times 10^{27}$ dyne-cm by Sieh et al. (1993). The geological estimate is likely a maximum, since considerably less slip occurred at depth along some portions of the fault than was observed at the surface and assumed to extend to a depth of $15 \mathrm{~km}$. An inversion of teleseismic surface waves (Kanamori et al., 1992) yielded a seismic moment of 1.1 $\times 10^{27}$ dyne-cm, but the average rigidity used was $10 \%$ larger than that in our study and accounts for some of the discrepancy.

It should not be surprising that the different data sets used in this study yield comparable estimates of seismic moment. Although it is commonly assumed that moments derived from very long-period data (such as sur-
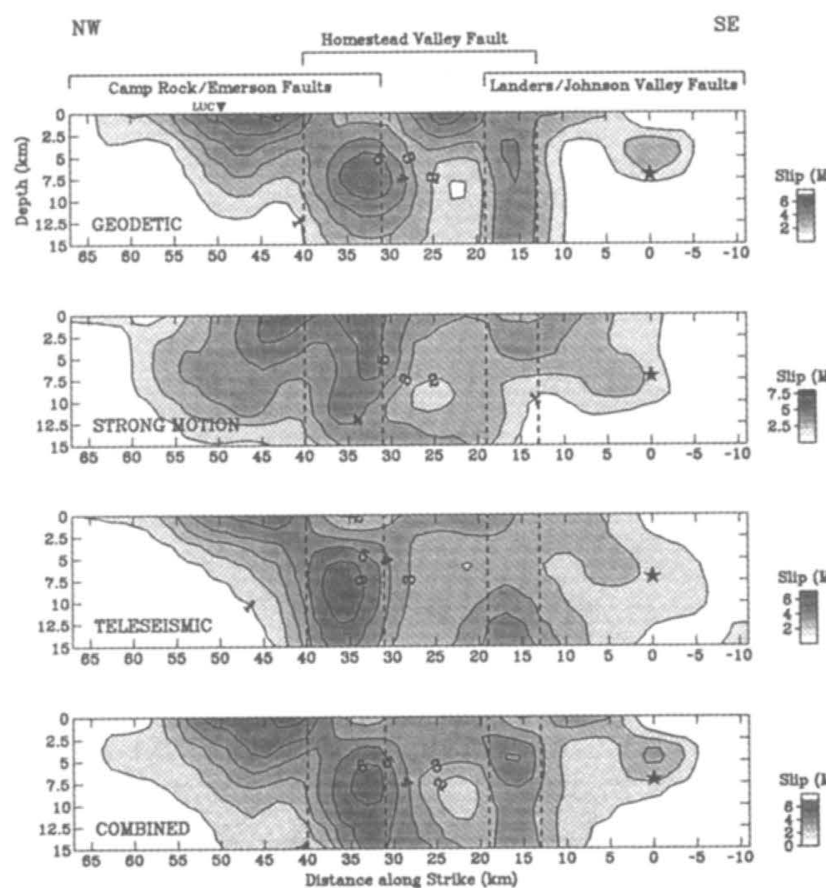

Stup (ML) 角

Figure 14. Comparison of separate inversion models: geodetic (top), strong motion (second), teleseismic (third), and combined results (bottom). Contour interval is $1 \mathrm{~m}$. face waves or geodesy) are significantly larger than moments derived from strong-motion data, there seems to be little evidence to support this viewpoint for shallow crustal earthquakes. On average, strong-ground-motion models from well-recorded earthquakes had moments equal to models derived from teleseismic body waves, longer-period surface waves, and geodetic data (Wald, 1992; Wald and Heaton, 1992). From these observations, we can conclude that the relatively short slip durations determined from modeling strong motions are in fact required. For the most part, these higher-frequency slip models do not appear to be missing significant longperiod slip.

The difference in the $M_{S} 7.6$ (National Earthquake Information Center, Preliminary Determination of Epicenters) versus the $M_{W} 7.2$ value determined here is consistent with that of other moderate and large earthquakes in California (Wald et al., 1993). The moment magnitudes, $M_{W}$, computed from the seismic moments determined from waveform modeling are usually significantly smaller than $M_{S}$ for California earthquakes. The 1906
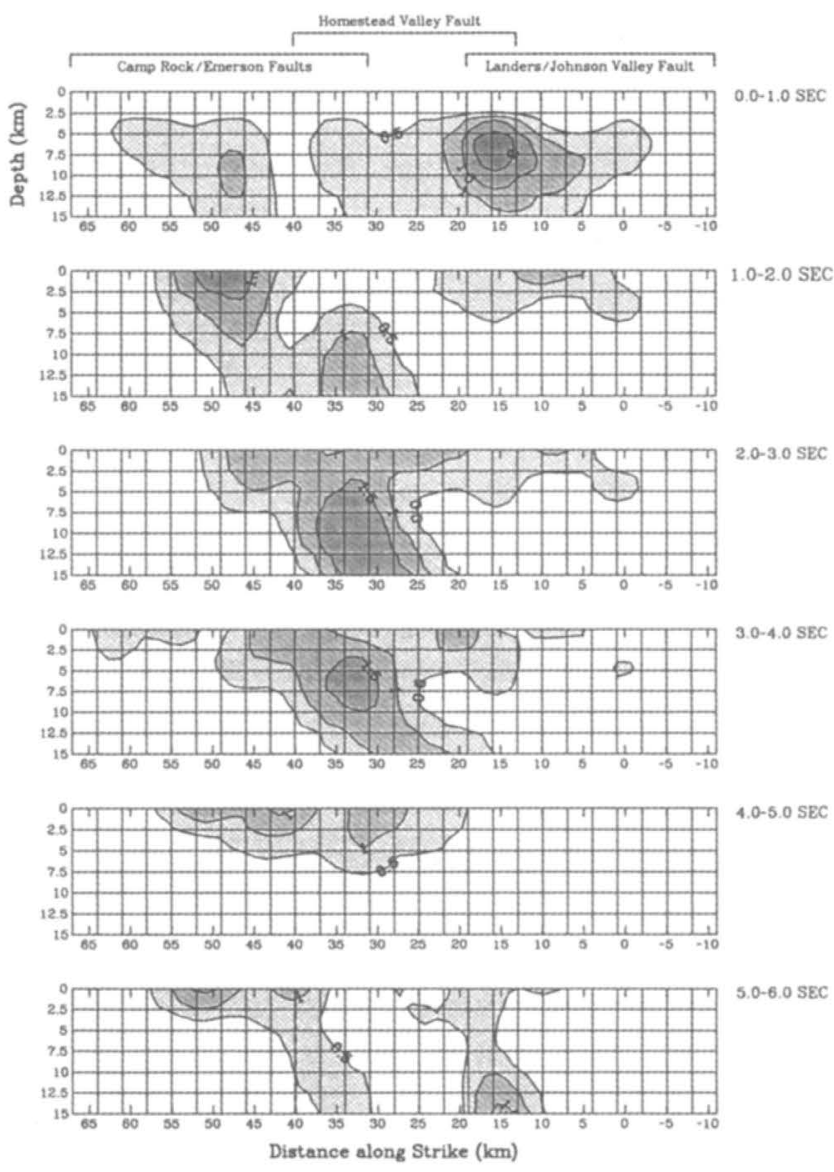

$5.0-6.0 \mathrm{SEC}$

Figure 15. Individual time-window contributions for the final slip model derived from all data sets combined (Fig. 13). The time at the right of each window gives the duration (see text for details). The contour interval is $0.5 \mathrm{~m}$. 


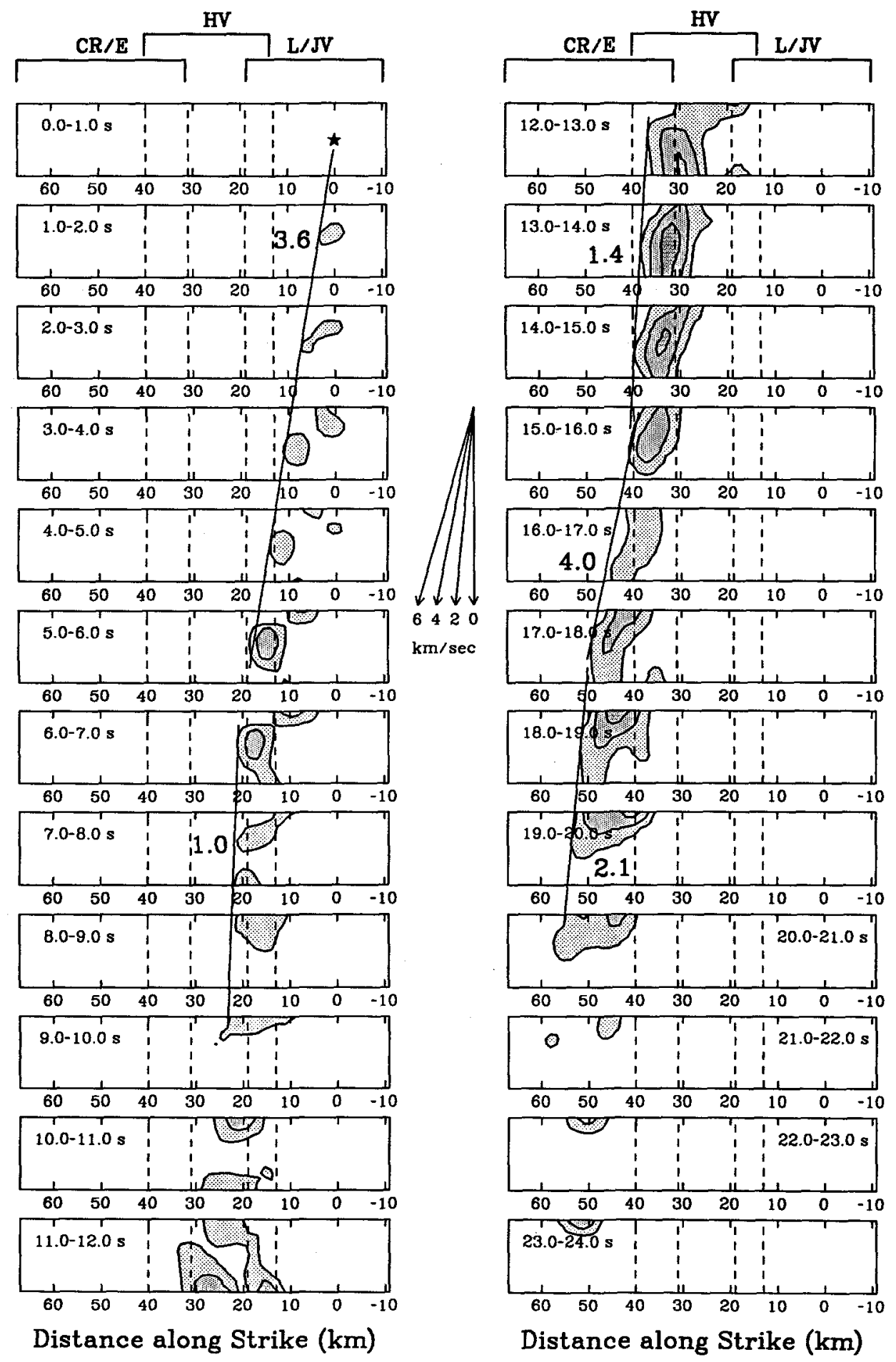

Figure 16. Time progression of the Landers rupture for the combined data model given at intervals of $1 \mathrm{sec}$ as labeled. The contour interval is $0.5 \mathrm{~m}$. For reference, a rupture velocity roset is given with arrows. Lines indicate selected regions of fairly constant rupture velocity. From top to bottom, these lines represent $3.6,1.0,1.4,4.0$, and $2.1 \mathrm{~km} / \mathrm{sec}$, respectively, as labeled. 
San Francisco earthquake had an $M_{S}$ of 8.3, yet an $M_{W}$ of 7.8 (Wald et al., 1993). Similarly, $M_{W}$ is 6.4 for the Imperial Valley event (Hartzell and Heaton, 1983), while $M_{S}$ is 6.9. This trend holds true for most other moderate to large California earthquakes (with the exception of the $1980 M_{S} 8.0$ Eureka and the $1971 M_{S} 6.5$ San Fernando events) and thus may be independent of focal mechanism. Since for events in this magnitude range $M_{S}$ is approximately the same as $M_{W}$, the above disparity between $M_{S}$ and $M_{W}$ suggests that the $M_{S}$ values for these events are overestimated. This bias can be partially explained by higher than average amplitudes along the travel path from California to Europe, where a disproportionately large number of stations are usually used for the $M_{S}$ determinations.

\section{Shallow versus Deep Slip}

Fault slip from the Landers earthquake had several significant characteristics. It had greater dislocations than many previous well-studied events, and the majority of the shallow rupture was within competent bedrock, rather than within sedimentary basins and valleys. It is often assumed that the surface offset from large earthquakes is simply related to the amount of faulting at depth. Our experience with moderate-sized events, however, should make this assumption questionable. Consider the many events in the magnitude 6 to 7 range for which adequate images exist for slip at depth that had little or no surface offset (e.g., 1992 Joshua Tree, 1989 Loma Prieta, 1984 Morgan Hill). Further, for the Landers earthquake, slip observed along the Camp Rock fault at the northern end of the rupture seems to be limited to the shallow portion of the fault. This feature is not only indicated by the geodetic and waveform modeling, but can also be inferred from the northwestern limit of aftershock activity (Fig. 1). That is, there were few aftershocks in the northernmost region in which large surface offsets were observed.

Although agreement between the amount of surface slip and dislocation at depth is apparent in a general sense for the Landers rupture, the peak surface slip is further north (Fig. 14, $45 \mathrm{~km}$ ) than that at depth (Fig. 14, 33 $\mathrm{km}$ ). A similar situation is seen for the central Homestead Valley fault section (Fig. 14, 20 to $25 \mathrm{~km}$ ) where slip is also confined to the shallow portion of the fault. In contrast, slip is primarily deep in the region near the hypocenter.

The occurrence of a mismatch between surficial and deeper slip may be partially explained in terms of prior slip history (Wald, 1992). Since many magnitude 6 to 7 events have little or no slip at the surface, either shallow slip must "catch up" by creep, or be made up during larger, through-going events. In the latter case, we would expect more shallow slip than deep slip over substantial lengths of the fault. Such observations recommend caution when relying on paleoseismic surface offset mea- surements to infer earthquake size, since they usually sample only a few points along a given rupture and may not be representative of slip that occurred at depth.

Figure 17 summarizes the effect of constraining slip in the top subfaults to be the surface offset. There are two regions which show a discrepancy between the shallow slip estimated with and without these slip constraints. The modeled slips (both unconstrained and constrained) along the Homestead Valley fault show a peak slip (at $16 \mathrm{~km}$ ) that is greater than the observed slip. In contrast, slip in the unconstrained model is less than was observed for most of the central Camp Rock/Emerson segment.

These features suggest several possibilities. First, we expect the largest variations in material properties near the free surface. Green's functions for our shallowest subfaults are likely to be less accurate than for deeper subfaults. Thus, our ability to resolve very shallow slip may be poor unless we use surface offset data. Second, our assumption that surficial slip is representative of the slip within the upper $2.5 \mathrm{~km}$ may be inappropriate. In fact, close examination of the surface offset data (Sieh et al., 1993) shows that the slip can change by more than a meter per kilometer along any fault trace. Such variations may not be representative of slip at depth.

Although the unconstrained model favors shallow slip that deviates in places from that observed, we can still fit the surface offset observations without substantially diminishing the fit to the other data. Furthermore, in-

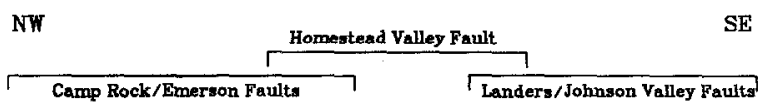

GEODETIC

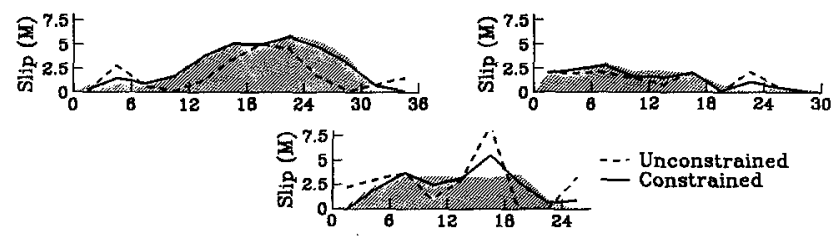

COMBINED

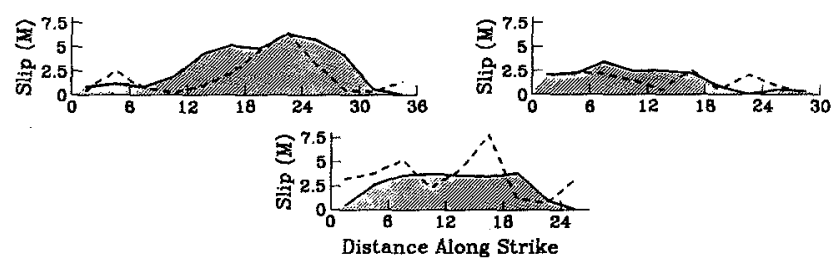

Figure 17. Comparison of shallow subfault slip values determined from the constrained (solid lines) and unconstrained (dashed lines) rupture models for both the geodetic and combined inversions. The fault segments are indicated at the top. Shaded areas represent observed surface slip as averaged over the subfault lengths. 
cluding the shallow-slip constraint does not significantly degrade the fit to the geodetic displacement vectors. Since we can adequately fit the surface-slip data as well as all the other observations, our preferred model includes the surface-slip constraint.

We attempted to correlate the spatial distribution of aftershock hypocenters from the Southern California Seismic Network (SCSN) catalog with our slip model. Inverse correlations between the spatial density of hypocenters and slip (such as summarized by Mendoza and Hartzell, 1988) are not clearly evident. However, there are serious questions about the accuracy of the hypocentral depths listed in the SCSN catalog for Landers aftershocks (Ma, 1993; Zhao and Kanamori, 1993). Thus, we feel it is inappropriate to show a correlation until future analysis can provide better depth control for the aftershocks.

\section{Forward Prediction of Ground Motions}

It was fortunate for southern Californians that the Landers earthquake struck such a sparsely populated region. Considering the size of this earthquake, it caused relatively little damage. Unfortunately, the near-source region was not only sparsely populated with people, but was also sparsely populated with strong-motion instruments. What were the ground motions like in the nearsource region? Although there was one station that recorded the near-source ground motions, it seems unlikely that the LUC record captured the largest ground motion, or that the LUC record is representative of all near-source sites. One way to estimate near-source ground motions is to use our preferred slip model to synthesize near-source ground motions at sites for which there are no recordings. Because we only inverted for ground motions that were low-pass filtered at $2 \mathrm{sec}$, we can only predict ground motions in this frequency range.

Synthetic ground velocities and displacements were computed on a $4-\mathrm{km}$ grid of stations within an $84-\mathrm{km}$ by $56-\mathrm{km}$ rectangular region (circles in Fig. 18) using the strong-motion dislocation model for the source (Fig. 12). Ground motions were computed at 330 locations in addition to the 16 original station locations (Table 2). The peak value of ground velocity was determined at each grid station, and then these values were contoured over the region. The contours of peak velocity are displayed in Figure 18 with a contour interval of $10 \mathrm{~cm} / \mathrm{sec}$. The peak velocity amplitudes are only valid within the bandwidth of the inversion modeling ( 2 to $14 \mathrm{sec}$ ), and although the results shown are for unfiltered synthetic waveforms, the F-K Green's functions were computed only up to $1 \mathrm{~Hz}$. For this reason, the predicted velocities represent a minimum estimate. For example, the observed peak velocities, when bandpassed similarly, were reduced in amplitude by over $30 \%$.

The westward concavity of fault rupture results in a slight focusing toward the west and defocusing toward the east as seen by the extension of the contours southwestward (Fig. 18). This is consistent with the observations; for example, there are comparable displacement amplitudes at Amboy (AMB) and Pasadena (PAS), although PAS is about $160 \mathrm{~km}$ from the central portion of the fault, and AMB is only $70 \mathrm{~km}$ away. While this exercise was aimed at near field predictions, it is straightforward to predict far-field time histories at particular locations in order to investigate triggered seismicity and similar phenomena elsewhere.

As a further exercise, to test the long-period aspects of our dislocation model, we predicted the TERRAscope displacement waveforms out to 100 -sec periods. Recall, the long-period cutoff used in our inversions was $13 \mathrm{sec}$, and this limitation was introduced by the long-period noise from integrating the digitized SMA1 film recordings. The TERRAscope strong motions, however, have much better fidelity, and waveform predictions from our combined inversion model produced waveform fits at the longer periods comparable to the match to the more bandlimited data shown in Figure 11. This supports the validity of our source model over a broad range of frequencies.

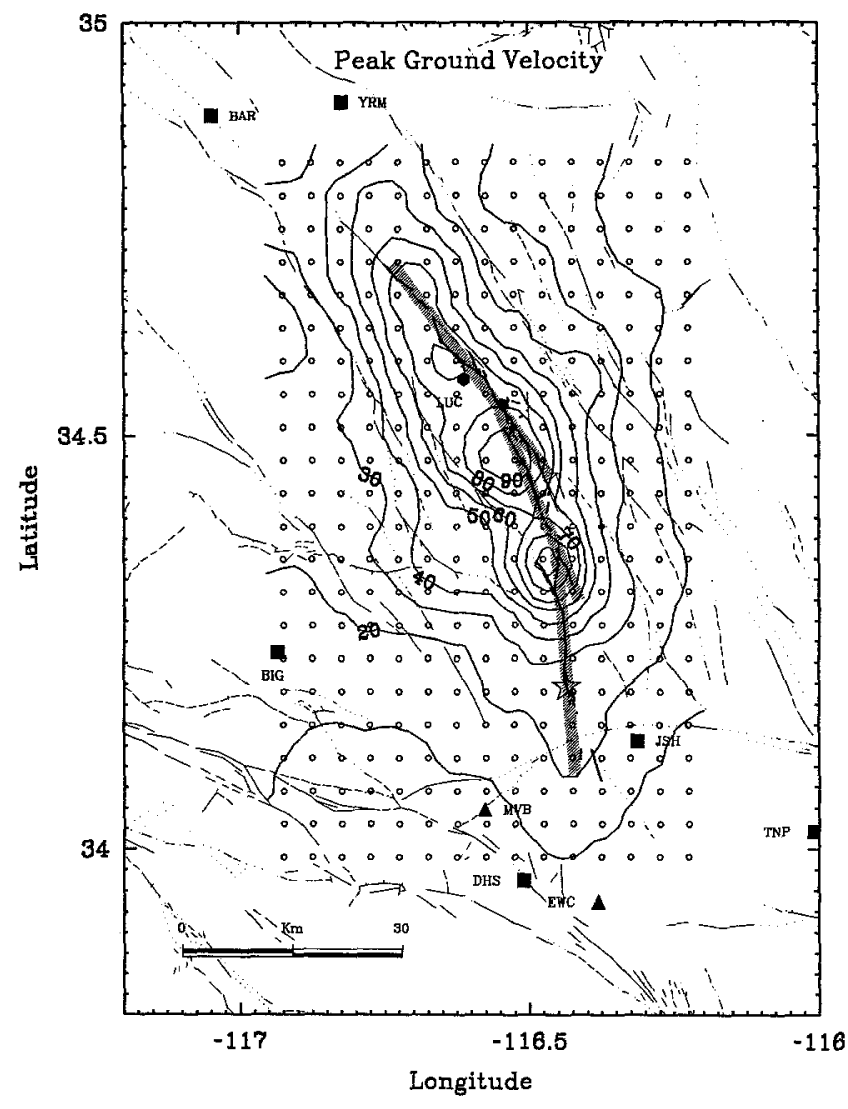

Figure 18. Map illustrating the grid of stations and the contoured distribution of peak ground velocities from the strong-motion forward prediction. 


\section{Conclusions}

Geodetic survey displacements, near-field and regional strong motions, broadband teleseismic waveforms, and surface offset measurements have been used, both independently and collectively, to determine a robust source rupture model for the 1992 Landers earthquake. Details of both the spatial and temporal slip variations determined from our inversions models are summarized below.

The strong ground motions required slip patterns and total dislocations comparable to longer-period teleseismic models and geodetic models (all the models have seismic moments in the range of about 7 to $8 \times 10^{27}$ dyne- $\mathrm{cm}$, and seismic potencies are 2.3 to $2.7 \mathrm{~km}^{3}$ ). The consistency in the slip models suggests that the total duration of slip was short. Furthermore, afterslip during the first month was limited to at most a few percent of the co-seismic slip.

Slip was extremely heterogeneous, both along strike and downdip, with peak slips near $7 \mathrm{~m}$ and variations of several meters over a distance of just a few kilometers. This spatial heterogeneity in the slip is inferred not only from the inverse modeling, but it is also observed in the surface offset data (Sieh et al., 1993). Variations of slip with depth relative to measured surface offsets were also clear; although the largest surface offsets were observed at the northern end of the rupture, substantial rupture was relatively shallow in that area compared to other regions of the fault where large slips persisted to a depth of at least $15 \mathrm{~km}$. These large slip variations seem to indicate that both strain increases and decreases were as large as $10^{-3}$ on the rupture surface. In some instances, fault rupture apparently results in a negative stress change. That is, regions with small slips (e.g., Fig. 13, 20 to 25 $\mathrm{km}$ along strike and 6 to $11 \mathrm{~km}$ deep) are often juxtaposed against regions of much higher slip. We speculate that this unusual behavior may be caused by dynamic instabilities in the rupture process (Heaton, 1990).

Alternatively, the slip heterogeneity can be attributed to earlier rupture sequences on these faults. For example, the slip of gap mentioned above may have been the location of an asperity during a prior magnitude 6 earthquake. Similarly, the lack of slip at depth on the northernmost portion Camp Rock fault, which showed much shallow slip, may be complementing prior slip from an event which never broke the surface (similar to the Joshua Tree earthquake). We suspect, though, that both prior rupture history and instabilities in the dynamic rupture process act in unison to control the overall rupture dimensions and slip variations.

As with other earthquakes modeled with sufficiently high-frequency data sets, the 1992 Landers earthquake requires short slip durations relative to the rupture duration, implying that only a portion of the fault is slipping at a particular time (as was emphasized by Heaton,
1990). Perhaps no better example of a propagating "slip pulse" has yet been imaged than that found in Figure 16. In general though; the capacity to resolve rupture propagation for the Landers earthquake can be attributed primarily to the large dimension and duration of the rupture and data diversity rather than superior strong-motion data coverage and quality. In fact, relative to many other strong-motion, finite-fault inversions for rupture characteristics, the near-field strong-motion station coverage for the Landers earthquake is rather sparse.

From our slip imaging, we can visually follow the progression of the rupture front. Over the 24-sec rupture duration of the earthquake, the average rupture velocity was $2.7 \mathrm{~km} / \mathrm{sec}$. In a general sense then, faulting proceeded from segment to segment as a single continuous rupture. In detail though, significant rupture velocity variations were apparent. Most notably, the rupture front slowed within regions of slip transfer from one fault segment to the next and near the termination of rupture at the northern Camp Rock fault.

In conclusion, we presented a finite-fault slip model that seems to explain most of the features of the surface offset data, the geodetic data, the strong-motion data (longer than 2-sec period), and the broadband teleseismic data. The most striking characteristics of the model are that the slip varies strongly with position on the fault and the slip duration is short, with little or no indication of afterslip.

\section{Acknowledgments}

We owe thanks to many for providing information and data. Jim Mori and Sue Hough helped access USGS FBA records, Dennis Ostrum and Bill Iwan helped with the SMA-2 data and response, Egill Hauksson supplied the relocated aftershock seismicity, and Jeff Freymueller, Ken Hudnut, and Mike Lisowski generously provided their surveyed and corrected (GPS and trilateration) displacements. Discussions with B. Cohee, D. Dreger, H. K. Thio, E. Hauksson, D. Helmberger, K. Hudnut, K. Sieh, and H. Kanamori added significantly to this work. Reviews by S. Hartzell, B. Cohee, and C. Ammon improved this manuscript. This work was supported in part by SCEC contract through USC No. 569933 funded by NSF EAR 89-20136 and by the U.S. Geological Survey under Contract No. 1433-93-G2322 while D.J.W. was at Caltech.

\section{References}

Abercrombie, R. and J. Mori (1994). Local observations of the onset of a large earthquake: 28 June 1992 Landers, California, Bull. Seism. Soc. Am. 84, no. 3, 725-734.

Dreger, D. (1994). Investigation of the rupture process of the June 28, 1992 Landers Earthquake utilizing TERRAscope, Bull. Seism. Soc. Am. 84, no. 3, 713-724.

Dullien, R. (1972). Laboratory evaluation of the SMA-2 magnetic tape-type strong motion accelerograph, C.I.T. Earthquake Engineering Research Laboratory, Pasadena, California.

Earthquake Engineering Research Institute (1992). EERI special earthquake report, August 1992, EERI Newsletter 26, 1-12.

Futterman, W. I. (1962). Dispersive body waves, J. Geophys. Res. 67, 5279-5291. 
Harris, R. A. and S. M. Day (1993). Dynamics of fault interaction: parallel strike-slip faults, J. Geophys. Res. 98, 4461-4472.

Hart, E. W., W. A. Bryant, and J. A. Treiman (1993). Surface faulting associated with the June 1992 Landers earthquake, California, Calif. Geol. 46, 10-16.

Hartzell, S. H. and T. H. Heaton (1983). Inversion of strong ground motion and teleseismic waveform data for the fault rupture history of the 1979 Imperial Valley, California earthquake, Bull. Seism. Soc. Am. 73, 1553-1583.

Hartzell, S. H. and T. H. Heaton (1986). Rupture history of the 1984 Morgan Hill, California, earthquake from the inversion of strong motion records, Bull. Seism. Soc. Am. 76, 649-674.

Hartzell, S. H. and C. Langer (1993). Importance of model parameterization in finite fault inversions application to the $1974 M_{W}$ 8.0 Peru earthquake, J. Geophys. Res. 98, 22123-22134.

Hartzell, S. H. and C. Mendoza (1991). Application of an iterative least squares waveform inversion of strong motion and teleseismic records to the 1978 Tabas, Iran, earthquake, Bull. Seism. Soc. Am. 81, 305-331.

Hauksson, E., L. M. Jones, K. Hutton, and D. Eberhart-Phillips (1993). The 1992 Landers Earthquake sequence: seismological observations, J. Geophys. Res. 98, 19835-19858.

Heaton, T. H. (1990). Evidence for and implications of self-healing pulses of slip in earthquake rupture, Phys. Earth Planet. Interiors $64,1-20$.

Hill, D. P., P. Rosenberg, A. Michael, W. Arabasz, G. Beroza, J. Brune, D. Brumbaugh, R. Castro, S. Davis, D. dePolo, W. Ellsworth, J. Gomberg, S. Harmsen, L. House, S. Jackson, M. Johnston, L. Jones, R. Keller, S. Malone, L. Munguia, S. Nava, J. Pechmann, A. Sanford, R. Simpson, R. Smith, M. Stark, M. Stickney, A. Vidal, S. Walter, V. Wong, and J. Zollweg (1993). Seismicity in the Western United States remotely triggered by the M 7.4 Landers, Califormia, carthquake of June 28, 1992, Science 260, 1617-1623.

Hough, S. E., J. Mori, E. Sembera, G. Glassmoyer, C. Mueller, and S. Lydeen (1993). Southern surface rupture associated with the 6/28/92 M7.4 Landers earthquake: did it all happen during the mainshock? Geophys. Res. Lett. 20, 2615-2618.

Hudnut, K. W., Y. Bock, M. Cline, P. Fang, J. Freymueller, K. Gross, D. Jackson, S. Larson, M. Lisowski, Z. Shen, and J. Svarc (1994). Co-seismic displacements in the Landers sequence, Bull. Seism. Soc. Am. 84, no. 3, 625-645.

Jennings, C. W. (1975). Fault map of California, with locations of volcanoes, thermal springs, and thermal wells, Calif. Div. Mines Geol., Geologic Data Map 1, scale 1:750,000.

Jones, L. E. and D. V. Helmberger (1992). Broadband modeling of aftershocks from the Landers, Big Bear, and Joshua Tree events, EOS 73, 383.

Kanamori, H., H. K. Thio, D. Dreger, E. Hauksson, and T. Heaton (1992). Initial investigation of the Landers, California, earthquake of 28 June 1992 using TERRAscope, Geophys. Res. Lett. 19, 2267-2270.

Kennett, B. L. N. and E. R. Engdahl (1991). Traveltimes for global earthquake location and phase identification, Geophys. J. 105, $429-465$.
Ma, Q. F. (1993). Broadband waveform observations of local earthquakes, Ph.D. Thesis, California Institute of Technology, Pasadena.

Langston, C. A. and D. V. Helmberger (1975). A procedure for modeling shallow dislocation sources, Geophys. J. 42, 117-130.

Mansinha, L. and D. E. Smylie (1971). The displacement field of inclined faults, Bull. Seism. Soc. Am. 61, 1433-1440.

Mendoza, C. and S. H. Hartzell (1988). Aftershock patterns and main shock faulting, Bull. Seism. Soc. Am. 61, 1438-1449.

Mendoza, C., S. H. Hartzell, and T. Monfret (1994). Wide-band analysis of the 3 March 1985 central Chile earthquake: overallsource process and rupture history, Bull. Seism. Soc. Am. (in press).

Murray, M. H., J. C. Savage, M. Lisowski, and W. K. Gross (1993). Coseismic displacements-1992 Landers, California, earthquake, Geophys. Res. Lett. 20, 623-626.

Shakal, A., M. Huang, T. Cao, R. Sherburne, R. Sydnor, P. Fung, P. Malhotra, C. Cramer, F. Su, R. Darragh, and J. Wampole (1992). CSMIP strong motion records from the Landers, California earthquake of 28 June, 1992. Report No. OSMS 92-09, California Strong Motion Instrumentation Program, 330 pp.

Sieh, K., L. Jones, E. Hauksson, K. Hudnut, D. Eberhart-Phillips, T. Heaton, S. Hough, K. Hutton, H. Kanamori, A. Lilje, S. Lindval, S. F. McGill, J. Mori, C. Rubin, J. A. Spotila, J. Stock, H. Thio, J. Treiman, B. Wernicke, and J. Zachariasen (1993). Near-field investigation of the Landers earthquake sequence, April to July, 1992, Science 260, 171-176.

Sylvester, A. G. (1993). Investigation of nearfield postseismic slip following the $M_{w} 7.3$ Landers earthquake sequence of 28 June 1992, California, Geophys. Res. Lett. 20, 1079-1082.

Wald, D. J., T. H. Heaton, and D. V. Helmberger (1991). Rupture model of the 1989 Loma Prieta earthquake from the inversion of strong motion and broadband teleseismic data, Bull. Seism. Soc. Am. 81, 1540-1572.

Wald, D. J., H. Kanamori, and D. V. Helmberger, and T. H. Heaton (1993). Source study of the 1906 San Francisco earthquake, Bull. Seism. Soc. Am. 83, 981-1019.

Wald, D. J. (1992). Rupture characteristics of California earthquakes, Ph.D. Thesis, California Institute of Technology, Pasadena.

Wald, D. J. and T. H. Heaton (1992). Comments on earthquake slip dynamics from comparative asperitology, $\operatorname{EOS~73,~} 383$.

Wald, D. J., D. V. Helmberger, and S. H. Hartzell (1990). Rupture process of the 1987 Superstitions Hills earthquake from the inversion of strong motion data, Bull. Seism. Soc. Am. 80, 10791098.

Wald, D. J., D. V. Helmberger, and T. H. Heaton (1991). The rupture initiation process of a large earthquake: Loma Prieta, Seism. Res. Lett. 62, 29.

Zhao, D. and H. Kanamori (1993). The 1992 Landers earthquake sequence: earthquake occurrence and structural heterogeneities, Geophys. Res. Lett. 20, 1083-1086.

U.S. Geological Survey

Pasadena, Califomia, 91106

Manuscript submitted 28 July 1993. 